\title{
Applications of phasor measurement units (PMUs) in electric power system networks incorporated with FACTS controllers
}

\author{
Bindeshwar Singh ${ }^{*}$, N.K. Sharma ${ }^{+}$, A.N. Tiwari ${ }^{*}$, K.S. Verma*, and S.N. Singh \# \\ "Department of Electrical Engineering, Kamla Nehru Institute of Technology, Sultanpur-228118 (UP), INDIA. \\ ${ }^{+}$Department of Electrical and Electronics Engineering, KIET, Muradnagar, Ghaziabad (UP), INDIA. \\ "Department of Electrical Engineering, Madan Mohan Malviya Engineering College, Gorakhpur-273010(UP), INDIA. \\ \#\# Department of Electrical Engineering, Indian Institute of Technology, Kanpur (UP), INDIA. \\ Emails: bindeshwar.singh2025@gmail.com,Tel+91-05362-240674, Fax. +91-05362-240674 (Bindeshwar Singh ${ }^{1}$, ${ }^{1}$ Corresponding Authors)), \\ drnikhlesh@gmail.com (N.K.Sharma),amerndee@rediffmail.com (A.N.Tiwari),ksv02@gmail.com (K. S. Verma), snsingh@iitk.ac.in (S. N. Singh)
}

\begin{abstract}
This paper presents a critical review on different application of Phasor Measurement Units (PMUs) in electric power system networks incorporated with FACTS controllers for advanced power system monitoring, protection, and control. Also this paper presents the current status of the research and developments in the field of the applications of PMUs in electric power system networks incorporated with FACTS controllers. Authors strongly believe that this survey article will be very much useful to the researchers for finding out the relevant references in the field of the applications of PMUs in electric power system networks incorporated with FACTS controllers.
\end{abstract}

Keywords: Flexible AC Transmission Systems (FACTS), FACTS Controllers, Phasor Measurement Units (PMUs), Electric Power System Networks.

\section{Introduction}

Synchronized phasor measurements are becoming an important element of wide area measurement systems used in advanced power system monitoring, protection, and control applications. Phasor measurement units (PMUs) are power system devices that provide synchronized measurements of real-time phasors of voltages and currents. Synchronization is achieved by same-time sampling of voltage and current waveforms using timing signals from the Gobal Positioning System Sattelite (GPS). Synchronized phasor measurement selevate the standards of power system monitoring, control, and protection to a new level (Heydt et al., 2001). The present and possible future applications of phasor measurement units have been well documented (EPRI final report, 1997).

A number of PMUs are already installed in several utilities around the world for various applications such as post-mortem analysis, adaptive protection, system protection schemes, and state estimation. One of the most important issues that need to be addressed in the emerging technology of PMUs is site selection. The intended system application influences the required number of installations. The cost of PMUs limits the number that will be installed although an increased demand in the future is expected to bring down the cost. The placement sites are also limited by the available communication facilities, the cost of which may be higher than that of the PMUs. A judicious choice of PMU locations is necessary to meet the criteria of cost and the intended PMU applications. PMUs become more and more attractive to power engineers because they can provide synchronized measurements of real-time phasors of voltage and currents (Nuqui et al., 2005). As the sole system monitor, state estimator plays an important role in the security of power system operations. Optimal placement of PMUs in power systems to enhance state estimation is a problem that needs to be solved. Several algorithms and approaches have been published in the open literatures.

In Chen et al. (2006), a strategic PMU placement algorithm is developed to improve the bad data processing capability of state estimation by taking advantage of the PMU technology. Techniques for identifying placement sites for PMUs in a power system based on incomplete observability are presented in (Nuqui et al., 2005), where simulated annealing method is used to solve the pragmatic communication-constrained PMU placement problem. A network of PMUs, known as the Wide Area Monitoring System (WAMS) (Hauer, 1997), is already available in Western Electricity Coordinating Council (WECC). The WAMS data had been analyzed for multiple purposes, including major blackout analysis (Kosterev D. N., 1999), model validation (Pereira, 2003), modal analysis (Hauer, 1991), and special control actions (Kosterev et al., 1998). Several major utilities have recently shown an interest in the synchronous phasor measurement technology. These include Hydro-Québec (Missout et al.,1993), American Electric Power (Schulz et al., 1997), the New York Power Authority, Electricity de France (EDF) (Faucon O., 1997) and many utilities of the Western Southern Coordinating Council (WSCC) (Mittelstadt, 1995; Bhargava, 1999; Kosterev, 1998) such as 
BPA and Southern California Edison Co. Accelerated by the fast convergence between high-capacity fiber-optics-based telecommunication network and a more effective management of distributed information systems through LANs and WANs, this trend will soon provide a reliable source of wide-area measurement of the dynamic state of the power systems (Mittelstadt, 1995).

This paper is organized as follows: Section 2 discusses the fundamentals of PMUs. Section 3 introduces the literatures survey on applications of PMUs in electric power system networks incorporated with FACTS controllers. Section 4 presents the results and discussion of the paper. Section 5 presents the conclusions of the paper.

\section{Fundamentals of PMUs}

PMUs technology provides phasor information (both magnitude and phase angle) in real time. The advantage of referring phase angle to a global reference time is helpful in capturing the wide area snap shot of the power system. Effective utilization of this technology is very useful in mitigating blackouts and learning the real time behavior of the power system. With the advancement in technology, the micro processor based instrumentation such as protection Relays and Disturbance Fault Recorders (DFRs) incorporate the PMU module along with other existing functionalities as an extended feature.

\subsection{Fundamentals of PMUs}

A pure sinusoidal waveform can be represented by a unique complex number known as a phasor. Consider a sinusoidal signal

$$
x(t)=X_{m} \cos (w t+\phi)
$$

The phasor representation of this sinusoidal is given by

$$
x(t)=\frac{X_{m}}{\sqrt{2}} e^{j \phi}=\frac{X_{m}}{\sqrt{2}}(\cos \phi+j \sin \phi)
$$

Note that the signal frequency $W$ is not explicitly stated in the phasor representation. The magnitude of the phasor is the rms value of the sinusoid $\frac{X_{m}}{\sqrt{2}}$ and its phase angle is $\phi$, the phase angle of the signal in (1). The sinusoidal signal and its phasor representation given by (1) and (2) are illustrated in Fig. 1.

Note that positive phase angles are measured in a counterclockwise direction from the real axis. Since the frequency of the sinusoidal is implicit in the phasor definition, it is clear that all phasors which are included in a single phasor diagram must have the same frequency. Phasor representation of the sinusoidal implies that the signal remains stationary at all times, leading to a constant phasor representation. These concepts must be modified when practical phasor measurements are to be carried out when the input signals are not constant, and their frequency may be a variable.

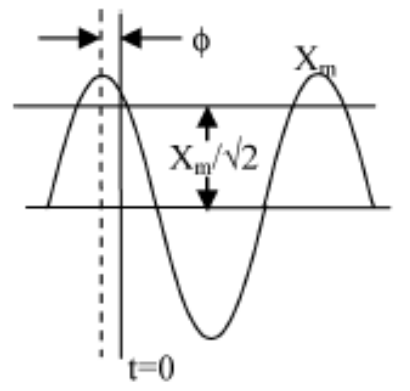

(a)

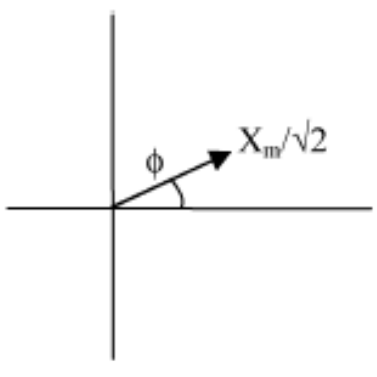

(b)

Fig. 1. Phasor representation of a sinusoidal signal. (a) Sinusoidal signal. (b) Phasor representation.

\subsection{Phasor Measurement Concepts}

Although a constant phasor implies a stationary sinusoidal waveform, in practice it is necessary to deal with phasor measurements which consider the input signal over a finite data window. In many PMUs the data window in use is one period of the fundamental frequency of the input signal. If the power system frequency is not equal to its nominal value (it is seldom), the PMU uses a frequency-tracking step and thus estimates the period of the fundamental frequency component before the phasor is estimated. It is clear that the input signal may have harmonic or non harmonic components. The task of the PMU is to separate the fundamental frequency component and find its phasor representation.

The most common technique for determining the phasor representation of an input signal is to use data samples taken from the waveform, and apply the Discrete Fourier Transform (DFT) to compute the phasor. Since sampled data are used to represent the input signal, it is essential that antialiasing filters be applied to the signal before data samples are taken. The antialiasing filters are analog devices which limit the bandwidth of 
the pass band to less than half the data sampling frequency (Nyquist criterion). If $x_{k}\{k=1,2,3, \ldots \ldots \ldots, N-1\}$ are the $\mathrm{N}$ samples of the input signal taken over one period, then the phasor representation is given by (Phadke and Thorp, 2008)

$$
X=\frac{\sqrt{2}}{N} \sum_{k=0}^{N-1} x_{k} e^{-j k \frac{2 \pi}{N}}
$$

The multiplier in front of the summation sign may need some explanation. Note that for real input signals, the components of the signal at a frequency $W$ appear in the DFT at $\pm W$ and are complex conjugates of each other. They can be combined, giving a factor of 2 in front of the summation sign in (3). The peak value of the fundamental frequency thus obtained is then converted to rms value by dividing by $\sqrt{2}$. The DFT calculation eliminates the harmonics of the input signal. However, the non-harmonic signals and any other random noise present in the input signal leads to an error in estimation of the phasor. The error of estimation due to these effects has been discussed in the open literatures.

\subsection{Synchrophasor Definition and Measurements}

Synchrophasor is a term used to describe a phasor which has been estimated at an instant known as the time tag of the synchrophasor. In order to obtain simultaneous measurement of phasors across a wide area of the power system, it is necessary to synchronize these time tags, so that all phasor measurements belonging to the same time tag are truly simultaneous. Consider the marker $t=0$ in Fig. 1 is the time tag of the measurement. The PMU must then provide the phasor given by (2) using the sampled data of the input signal. Note that there are antialiasing filters present in the input to the PMU, which produce a phase delay depending upon the filter characteristic. Furthermore, this delay will be a function of the signal frequency. The task of the PMU is to compensate for this delay because the sampled data are taken after the antialiasing delay is introduced by the filter. This is illustrated in Fig. 2. The synchronization is achieved by using a sampling clock which is phase-locked to the one-pulse-per-second signal provided by a GPS receiver. The receiver may be built in the PMU, or may be installed in the substation and the synchronizing pulse distributed to the PMU and to any other device which requires it. The time tags are at intervals that are multiples of a period of the nominal power system frequency. It should also be noted that the normal output of the PMU is the positive sequence voltage and current phasors. In many instances the PMUs are also able to provide phasors for individual phase voltages and currents (Revision of IEEE Std 1344, 1995).

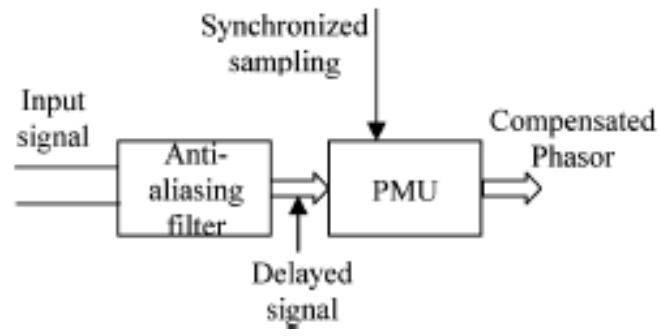

Fig. 2. Compensating for signal delay introduced by the antialiasing filter.

\subsection{Applications of PMUs in Power Systems}

The synchronized phasor measurement technology is relatively new, and consequently several research groups around the world are actively developing applications of this technology. It seems clear that many of these applications can be conveniently grouped as follows:

- $\quad$ Power System Real Time Monitoring

- Advanced network protection

- $\quad$ Advanced control schemes

\subsection{Outlook of PMUs}

PMUs facilitate innovative solutions to traditional utility problems and offer power system engineers a whole range of potential benefits, including:

- $\quad$ Precise estimates of the power system state can be obtained at frequent intervals, enabling dynamic phenomena to be observed from a central location, and appropriate control actions taken.

- $\quad$ To ensure acceptable quality of the power supplied to the consumers.

- $\quad$ Post-disturbance analyses are much improved because precise snapshots of the system states are obtained through GPS synchronization.

- To analyze the vulnerability of the system against any contingency. This is known as security assessment of the power system networks. 
- $\quad$ Advanced protection based upon synchronized phasor measurements could be implemented, with options for improving overall system response to catastrophic events.

- $\quad$ Advanced control using remote feedback becomes possible, thereby improving controller performance.

\subsection{The Global Positioning Satellite (GPS) Systems}

The GPS system consists of 24 satellites in six orbits at an approximate altitude of 10,000 miles above the surface of the earth. They are thus approximately at one half the altitudes corresponding to a geo-synchronous orbit. The positioning of the orbital plane and the positioning of the satellites in the orbits is such that at any given instant at least four satellites are in view from any point on the surface of the earth. Often, more than six satellites are visible.

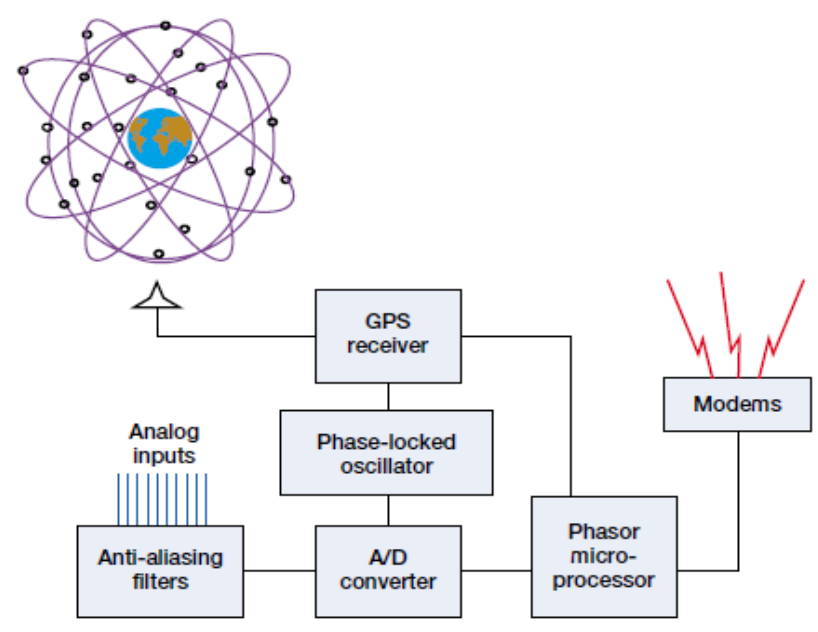

Fig.3. Block diagram of the Phasor Measurement Unit

The civilian-use channel of the GPS system transmits positional coordinates of the satellites from which the location of a receiver station on earth could be determined. In addition, the satellites transmit a one-pulse per- second signal, along with an identifier for the signal that can be interpreted by the earth station receivers. The civilian-use transmission of the time signal is precise to within 1 microsecond, and often in practice is found to be much more accurate. The time pulse is of critical importance to the application considered here. The normal practice is to phaselock a sampling clock to this pulse. The sampling instant would be identified as the pulse number within a one-second interval identified by the GPS time-tag. The exact format for time-tagging is defined in IEEE standard 1344 (EPRI Final Rep., April, 1997). It should be mentioned that a time standard known as the IRIG-B standard is currently being used by the power industry for time-tagging digital fault recorders and other substation event monitoring systems. However, with standard IRIG-B receivers the synchronization accuracy is of the order of 1 millisecond, which is not enough for precise power system measurement (a tolerance of 1 millisecond corresponds to an uncertainty of about $20^{\circ}$ ).The Complete block diagram of PMUs and PMUs utilization in power systems are shown in Fig. 3. \& 4.

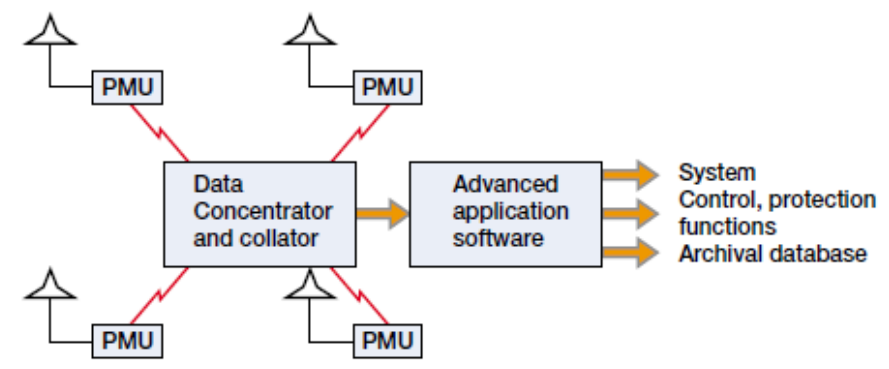

Fig.4. PMU utilization in a power system

The various features of PMUs are given below as follows:

- $\quad$ PMUs are Measures 50/60 Hz AC waveforms (voltage and current) typically at a rate of 48 samples per cycle.

- $\quad$ PMUs are then computed using DFT-like algorithms, and time stamped with a GPS.

- $\quad$ The resultant time tagged PMUs can be transmitted to a local or remote receiver at rates up to 60 samples per cycle. 


\subsection{Main strategy of PMU placement Based on Power Systems Intrinsic Characteristics}

For the purposes of real-time dynamic performance monitoring the power system operating conditions, WAMS should have following monitoring functions:

- $\quad$ Key lines and links reflect the main system characteristics

- Substations on key system interties and major load areas

- Key system generating plants

- Key system substations

- $\quad$ Key devices, such as HVDC, SVC, TCSC and other FACTS devices

- $\quad$ Special protection systems and remedial action schemes

Overall measurement facilities must support:

- $\quad$ Real-time observation of system performance

- $\quad$ Recording and analysis of system disturbances

\subsection{The Comparisons between SCADA system and PMUs System}

The following comparisons between SCADA and PMUs systems are given in below in Table 1.

\begin{tabular}{|l|l|l|}
\hline \multicolumn{1}{|c|}{ Attribute } & \multicolumn{1}{c|}{ SCADA } & \multicolumn{1}{c|}{ PMUs } \\
\hline Measurement & Analogue & Digital \\
\hline Resolution & $\begin{array}{l}\text { 2-4 samples per } \\
\text { cycle }\end{array}$ & $\begin{array}{l}\text { Up to 60 samples per } \\
\text { cycle }\end{array}$ \\
\hline Observability & Steady State & Dynamic/Transient \\
\hline Monitoring & Local & Wide- Area \\
\hline $\begin{array}{l}\text { Phasor Angle } \\
\text { Measurement }\end{array}$ & No & Yes \\
\hline
\end{tabular}

From Above Table1 it is concluded that the PMUs are gives more accurate and efficient results as comparisons of SCADA systems.

\section{A Literatures Survey on Applications of PMUs in Electric Power System Networks Incorporated with FACTS Controllers}

The applications of PMUs such as monitoring, control and protection in power system networks are discussed in details in this section

\subsection{Optimal Placement of PMUs in Power System Networks}

In Almutairi and Milanovi (2009) compare three different methods for optimal placement of PMUs. The objective of the placement methods is to provide the maximum observability information of the electromechanical modes of interest. The first method is based on the observability factor analysis, the second on the sequential orthogonalization algorithm and the third combines coherency identification technique with the observability factor analysis. Kerdchuen and Ongsakul (2008) suggested a hybrid genetic algorithm and simulated annealing (HGS) for solving optimal placement of PMU and RTU for multi-area power system state estimation. Each power system control area includes one PMU and several RTUs. Voltage magnitude, voltage angle, and real and reactive current are measured by PMU while the injection and flow of real and reactive power are measured and monitored through RTU. The power injection and flow measurement pairs are placed to observe the raw data of boundary bus and tie line for data exchange in wide-area state estimator. In (Gou B., 2008), presented a simple optimal placement algorithm of PMUs by using integer linear programming. Cases with and without conventional power flow and injection measurements are considered. The measurement placement problems under those cases are formulated as an integer linear programming which saves the CPU computation time greatly. Sodhi and Srivastava (2008) presented a two level approach for solving optimal PMU placement (OPP) problem in order to achieve complete observability of the power system. The proposed approach in this literature is utilizes a heuristic algorithm to partition the power system into two or more sub-networks. The algorithm partitions the spanning tree of the network using integer linear programming (ILP). The ILP has been formulated based on eigenvectors of the adjacency matrix of the spanning tree. After decomposition, PMUs have been placed optimally in the sub-networks in order to minimize installation cost of the PMUs. Nuqui and Phadke (2005) presented techniques for identifying placement sites for PMUs in a power system based on incomplete observability. The novel concept of depth of unobservability is introduced and its impact on the number of PMU placements is explained. Initially, we make use of spanning trees of the power system graph and a tree search technique to find the optimal location of PMUs. Donolo and Centeno (2005) proposed two procedures to compute the quality of phasor estimations. These procedures will enable PMUs to report, with each measurement, the quality of the estimated phasor. The procedures rely solely on measured data and are independent of the algorithm used to obtain the phasor estimate.

In Baldwin et al. (1993), a minimal phasor measurement placement method based on the topological observability theory using graph theorem analysis is proposed. The measurement set is found through both a modified bisecting search and simulated annealing-based method. In Milosevic and Begovic (2003), the PMUs placement method based on the non-dominated sorting genetic algorithm is proposed. The individual optimal solution of objectives is estimated by the graph theory procedure and simple genetic algorithm. Then the best tradeoff between 
competing objectives is searched by using non-dominated sorting genetic algorithm. In Xu and Abur (2004), integer programming based on network observability formulation is applied to find the optimal PMUs placement. This method can be applied to the case of mixed measurement set which PMUs and conventional measurements are included into the system. A heuristic technique based on the minimum condition number of the measurement matrix and a sequential elimination is proposed (Madtharad et al., 2003). Chawasak et al. (2007) presented a new method for an optimal measurement placement of PMUs for power system state estimation. Mao et al. (2008) developed a systematic methodology for placement and integration of wide-area measurements in high-voltage direct current (HVDC) damping modulation for large-scale AC/DC power system. In Chen and Abur (2008), a topology error, which constitutes one of the significant source of problems for today's state estimators was reported. They may cause significant biases in state estimation solutions and may occasionally lead to divergence of the numerical solution algorithms. In Corsi (2009), a V-WAP system based on this method requires more than one installation of PMUs on the main HV buses in the considered wide area jointly with real-time identifiers of local buses voltage instability risk indicators. Based on the wide-area indices values, a proper and timely load shedding (LS) has to be progressively ordered around the bus with the highest index value. Modern-day power systems are being operated under heavily stressed conditions to cater for the rapidly growing demand for electricity, and to maintain an economic operation under a highly competitive deregulated environment (Phadke et al., 1983). A wide area monitoring, protection, and control (WAMPAC) system is therefore becoming increasingly essential for improved power system planning, operation, maintenance, and energy trading (Novosel et al., 2008). Baldwin et al. (1993) addressed the placement of a minimal set of PMUs so as to make the system placed at a bus measures the voltage as well as all the current phasors at that bus, requiring the extension of the topological observability theory. Chakrabarti and Kyriakides (2008) proposed a method for optimal placement of PMUs for complete observability of a power system for normal operating conditions, as well as for single branch outages. A binary search algorithm is used to determine the minimum number of PMUs needed to make the system observable. In case of more than one solution, a strategy is proposed to select the solution resulting in the most preferred pattern of measurement redundancy. (Aminifar et al., 2009), investigated the application of immunity genetic algorithm (IGA) for the problem of optimal placement of PMUs in an electric power network. PMUs have evolved into a practical tool for measurement of positive sequence associated with power system voltage and current phasors. These devices are synchronized via signals from GPS transmission. They can enhance many present applications such as state estimation and bad data detection, and stability control (Kosterev et al., 1998), remedial action schemes (Bertsch et al., 2005), and disturbance monitoring (Zhong et al., 2005). As the voltage and current phasors are measured, the equations of state estimation problem become linear and the solution can be obtained straightforwardly (Zivanovic and Cairns, 1996). It is neither economical nor necessary to install a PMU at each bus of a wide-area power network. As a result, the problem of optimal PMU placement (OPP) concerns with where and how many PMUs should be implemented to a power system to achieve full observability at minimum number of PMUs. The theory of network observability can be divided into two groups of techniques: numerical and topological (Peng et al., 2006). The former is based on whether the measurement gain or Jacobian matrix is of full rank or not. This technique suffers from huge matrix manipulation which means being computationally expensive. The latter, as the commonly used technique, is however based on whether the spanning tree of full rank can be constructed or not. Reference (Cho et al., 2001), proposed three approaches aiming at reducing computational burden of the OPP problem. First, SA method was modified in setting the initial temperature and cooling procedure. Second, direct combination (DC) method was suggested using a heuristic rule to select the most effective sets in the observability sense. Last, Tabu search (TS) method was employed to reduce the searching space effectively. The literatures appeared after this paper revealed that its results were not the optimal values even in small studied cases. A GAbased procedure for solving the OPP problem was presented in Marın et al. (2003). There is no implication on the aspects of converging speed and execution time. Also, the examined test systems are relatively small comparing to those needed in practice. Referring to the above mentioned features associated with different techniques, it is evident that most of the introduced methods suffer from a very time consuming process to reach a near-global optimum.

In Jiao and Wang (2000), IGA was developed and its effectiveness was verified on the traveling salesman problem (TSP) as a benchmark. It was revealed that IGA is not only feasible but also effective and is conducive to alleviate the degeneration phenomenon in the original GA, thus greatly increases the converging speed. The main idea behind IGA is employing the prior knowledge of problem in the search process. In (Chakrabarti et al., 2009), demonstrated the uncertainties associated with the power system state variables obtained with the help of PMUs. An integer-quadratic programming- based method is used to determine the minimum number and the optimal locations of the PMUs to ensure complete topological observability of the system. In recent years, there has been a significant research activity on the problem of finding the minimum number of PMUs and their optimal locations for power system state estimation (Chakrabarti and Kyriakides, 2007).

An integer-quadratic-programming-based method for finding the optimal PMU locations for complete power system observability is described in Chakrabarti et al. (2007). The method achieves multiple objectives: it minimizes the required number of PMUs and maximizes the measurement redundancy at all the buses. During power system restoration, it is necessary to check the phase angle between two buses before closing circuit breakers to connect a line between them. A novel approach for reducing large standing phase angle (SPA) based on Genetic Algorithm (GA) is presented in this literature. The proposed approach starts with a state estimation on WAMS data measurements and considering power system operation and angular stability constraints, seeks an optimal control action scenario for reducing SPA. Since these constraints are evaluated based on WAMS data, the presented approach is considerably high speed and accurate. As an optimization problem, objective function of the proposed approach is to minimize variation from the current state of the power system (Nourizadeh et al., 2010). Emami and Abur (2010) is concerned about optimal placement of synchronized phasor measurements that can monitor voltage and current phasors along network branches. Earlier investigations on placement of PMUs have assumed that PMUs could be placed at a bus and would provide bus voltage phasor as well as current phasors along all branches incident to the bus. In Lin et al. (2004), a new fault detection/location technique with consideration of arcing fault discrimination based on PMUs for extremely high voltage/ultra-high voltage transmission lines is presented in this literature. Synchronized phasor measurements from a limited number of dispersed locations in the power grid can be used for enhanced monitoring of the power system, as well as for presentation of the critical dynamics in the power system (Samuelsson, 2000). Gou (2008)'s work is based on the integer linear programming formulation proposed for optimal PMU placement, this literature has been presented a generalized integer linear programming formulation for cases including redundant PMUs placement, full observability and incomplete observability.

Due to accurate voltage phasor measurement and current phasor measurements provided by PMUs, the accuracy, redundancy and thus the robustness of state estimation will be enhanced with the integration of PMU measurements. Recently, the authors proposed in ref. (Kamwa I., et al., 2009), a clustering approach based on the Fuzzy C-medoid algorithm (FCMdd), for segregating large power systems into coherent electric areas centered around a representative so-called medoid-bus. This bus was shown to be a natural location for PMU in the context of wide-area measurement system (WAMS) configuration for of dynamic vulnerability assessment (DVA). In Aminifar et al. (2010), a model for the optimal 
placement of contingency-constrained PMUs in electric power networks is presented. The conventional complete observability of power networks is first formulated and then, different contingency conditions in power networks including measurement losses and line outages are added to the main model.

\subsection{Power System Real Time Monitoring}

Fan and Centeno (2007) stated that a phasor-based frequency measurement technique has very good steady-state performance, but their dynamic performance is not well documented. This literature analyzes a phasor-based frequency measurement method that considers the effect of dynamic frequency, and proposed a method to improve the dynamic performance of the phasor-based frequency measurements. Phadke and Kasztenny, 2009), presented a synchronized phasor measurements are becoming an important element of wide area measurement systems used in advanced power system monitoring, protection, and control applications. Kamwa et al. (2009) proposed a systematic scheme for building compact and transparent fuzzy rule-based classifiers for rapid stability assessment; the classifiers are initialized by large accurate decision trees (DTs). The approach starts by selecting strategic monitoring buses where PMUs are placed to capture wide-area response signals in real-time operation. Aminifar et al., 2010) stated that probabilistic analyses of a WAMS would require equivalent reliability models for its components which include PMUs. In this literature, the reliability modeling of PMU is proposed and the proposed model is extended to consider options for the PMU hardware. Recently, wide area monitoring of power system based on multiple phasor measurements has been put into the spotlight by many engineers and practitioners. Phasor measurement unit (PMU), equipped with the GPS, gives the opportunity of data synchronization at a common time reference. With the GPS, the time stamp is accurate to within 1 microsecond at any location on the earth. Accordingly, observed phasor data measured at multiple locations can be synchronized with high accuracy (Kakimoto, et al., 2006). Moreover, oscillation modes, especially the inter-area low-frequency mode with poor damping, can be detected from measured data by modeling measured data via a simplified oscillation model (SOM) (Hashiguchi et al, 2004). Joana and Preben, 2006 used two sets of synchronized phasor measurements $200 \mathrm{~km}$ apart during a planned outage of a double 400-kV tie-line between Eastern Denmark and Southern Sweden. The interconnection between Eastern Denmark and Southern Sweden is comprised of a double 400-kV line and a double 132-kV line. Messina and Vittal (2007) presented an approach based on the empirical mode decomposition (EMD) technique and proper orthogonal decomposition is proposed to examine dynamic trends and phase relationships between key system signals from measured data. Drawing on the EMD approach, and the method of snapshots, a technique based on the notion of proper orthogonal modes, is used to express an ensemble of measured data as a linear combination of basic functions or modes.

Kamwa et al. (2007) proposed a technique for partitioning a large power system into a number of coherent electric areas for possible application to dynamic vulnerability assessment. The coherency concept and a fuzzy clustering algorithm grouping of buses are combined to achieve this goal. The clusters are obtained by selecting representative buses from the data set in such a way that the total fuzzy dissimilarity within each cluster is minimized. The initialization problem of the conventional Fuzzy c-means algorithm, which usually leads to multiple solutions, is suitably tackled by incorporating the maximum-dissimilarity based sequential PMUs placement technique. During 2005 and 2006, the WECC performed three major tests of western system dynamics. These tests used a WAMS based primarily on PMUs to determine response to events including the insertion of the 1400-MW Chief Joseph braking resistor, probing signals, and ambient events. Test security was reinforced through real-time analysis of wide-area effects, and high-quality data provided dynamic profiles for inter-area modes across the entire western interconnection. The tests established that low-level optimized pseudo-random+-20-MW probing with the Pacific DC Intertie (PDCI) roughly doubles the apparent noise that is natural to the power system, providing sharp dynamic information with negligible interference to system operations. Such probing is an effective alternative to use of the 1400-MW Chief Joseph dynamic brake, and it is under consideration as a standard means for assessing dynamic security (John et al., 2009). A power system frequency monitoring network (FNET) was first proposed in 2001 and was established in 2004. As a pioneering WAMS, it serves the entire North American power grid through advanced situational awareness techniques, such as real-time event alerts, accurate event location estimation, animated event visualization, and post event analysis. Several papers published in the past several years discussed the FNET structure and its functionality. This paper presents some of the latest implementations of FNET's applications, which add significant capacities to this system for observing power system problems (Zhang et al., 2010).

\subsection{Power System Operation, Control, and Planning}

The voltage and current phasors measured by the PMUs at widely dispersed locations are time-stamped with respect to a GPS clock (Phadke et al. 1994). To determine the confidence levels associated with the state variables obtained by using the PMUs, it is needed to evaluate the corresponding uncertainties. The main sources of measurement uncertainties are: 1) the instrument transformers; 2) the analog interfaces, including cables, connecting the instrument transformer and the digital equipment; and 3) the analog to- digital converters (ADCs) and the associated computational algorithm (Zhu et al., 2006). In this literature, the uncertainty associated with the voltage magnitudes and phase angles at the buses, as determined by the PMUs, is evaluated using three different approaches: the classical uncertainty propagation theory (ISO-IECOIML-BIPM, 1992), the Monte Carlo method (JCGM YYY: 2006), and the use of random fuzzy variables (RFVs) (Ferrero, 2004; 2006). Precise time-synchronized phasor measurements are available to us today from the PMUs.One of the most promising uses of the PMU is for during transient control applications. The work reported in this literature by Stewart et al. (1995) investigated the ability of synchronized Phase Angle Measurements to identify impending instabilities through real time measurements and to trigger remedial actions in time to prevent major power system outages.

Kamwa et al. (2001) addressed the capability of the emerging synchronized phasor measurement technology in improving the overall stability of the Hydro-Quebec's transmission system through supplementary modulation of voltage regulators. Frequency recording units (FRUs), designed to measure power systems' frequency at low voltage, are affected by the connection of large loads causing sudden phase shifts and magnitude changes in the voltage. These phase shifts introduce spikes in the frequency measured by FRUs. In this literature, proposed an algorithm to detect the phase shifts and to produce accurate frequency estimation regardless of load changes (Marcos et al., 2006). Aranya et al. (2009) developed a measurement-based method for estimating a two-machine reduced model to represent the inter-area dynamics of a radial, two-area power system with intermediate dynamic voltage control. Two types of voltage control equipment are considered, namely, a static VAr compensator (SVC), and a synchronous condenser. 


\subsection{Application of PMUs for Fault detection/Location of Power Systems}

Lee et al. (2006) presented a new numerical algorithm for fault location estimation and for faults recognition based on the synchronized phasors. The proposed algorithm in this literature is based on the synchronized phasor measured from the synchronized PMUs installed at twoterminals of the transmission lines. Yu et al. (2002) suggested a new fault location algorithm based on PMUs for series compensated lines. Traditionally, the voltage drop of series device is computed by the device model in the fault locator of series compensated lines, but using this approach errors are induced by the inaccuracy of the series device model or the uncertainty operation mode of the series FACTS device. The proposed algorithm does not utilize the series device model and knowledge of the operation mode of the series device to compute the voltage drop during the fault period. Instead, the proposed algorithm uses two-step algorithm, pre-location step and correction step, to calculate the voltage drop and fault location.

Lin et al. (2004) addressed a new fault detection/location technique with consideration of arcing fault discrimination based on PMUs for extremely high voltage/ultra-high voltage transmission lines is presented in this literature. Literature I of this two-literature set is mainly aimed at theory and algorithm derivation. In (Jiang et al., 2000), literature I of this literature set sets forth theory and algorithms for adaptive fault detection/location technique, which is based on Phasor Measurement Unit (PMU). This literature is Part II of this literature set. A new timing device named "Global Synchronism Clock Generator, (GSCG)" including its hardware and software design is described in this literature. In (Pereira et al., 2004), a PMUs optimized allocation allows control, monitoring and accurate operation of electric power distribution systems, improving reliability and service quality. Good quality and considerable results are obtained for transmission systems using fault location techniques based on voltage measurements. In Chuang et al. (2007), a modern fault detection/location technique for an EHV/UHV transmission network usually works based on the data measured by PMUs has been proposed in this literature. The synchronized voltage and current phasors measured by PMU are transmitted to a monitoring center for analysis. Recently, PMUs has been widely used for fault location. Jiang et al. (2000; I, II) presented PMU-based fault detection technique for transmission lines. The GSCG can provide reliable reference clock signal to ensure the sampling synchronization accuracy.

Yu et al. (2002) developed PMU-based fault location algorithm for series FACTS compensated lines. Pre-location and correction steps are used to eliminate the errors induced by series device model. An advantage of PMU-based method is lower sampling rate compared with abovementioned methods. Chen et al. (2008) stated that power systems are extraordinary dynamic and complicated systems with various components and tools of generation, transmission, distribution, protection and control to guarantee the nation-wide interconnected grid's daily operation and safety. This literature reviews the latest PMUs technology development and applications in power system dynamic analysis and reduced model parameter estimation, event and fault location, and novel control strategies and algorithms employed in validating relay operations to prevent cascading failure. Although PMUs have become increasingly widespread throughout power networks, the buses monitored by PMUs still constitute a very small percentage of the total number of system buses. Our research explores methods to derive useful information from PMU data in spite of this limited coverage. In particular, we have developed an algorithm (Tate and Overbye, 2008) which uses known system topology information, together with PMU phasor angle measurements, to detect system line outages. In addition to determining the outaged line, the algorithm also provides an estimate of the pre-outage flow on the outaged line. Brahma (2007) described a new iterative method to locate fault on a single transmission line. The method uses synchronized voltage and current measurements from both line terminals. Using the positive sequence components of the pre-fault and the post-fault phasors, positive sequence source impedances at both terminals are first estimated. Girgis et al. (1992), Jiang et al. (2000) and Gopalakrishnan et al. (2000) used voltage and current phasors from both ends. Girgis et al also show techniques to remove synchronization errors. They used three phase analysis and use a least square estimate to obtain the fault point distance by solving six equations. However, this method does not take line capacitance in to account. For faults with higher resistance, the charging currents in the line capacitance will introduce errors in the results. Jiang et al derive a fault location index from a phasor model based on transmission line equations. Gopalakrishnan et al. (2000) adopt a time domain model of a transmission line for development of their algorithm. The method is tested on very limited number of test-cases and the effect of fault resistance is not reported. In (Djuric et al., 1998), has been presented a numerical algorithm utilizing the pre-fault and the post-fault current phasors from one end of the line. However, the algorithm is designed only for phase to ground faults. Tawfik et al. (2001) used Prony method to convert time domain samples to frequency domain and then use artificial neural network to estimate the fault location. Heuristic methods like this require very exhaustive training, which is difficult to achieve. In (Zamora et al., 1996; Brahma et al.,2004; Pereira et al., 2004; Lin et al., 2004), reported the fault location methods that require the source impedance at line terminals. In Hauer et al. (1996), faults applied during March 1993 commissioning tests for the California-Oregon Transmission Project produced $14 \mathrm{~Hz}$ transient oscillations that were conspicuous in BPA's enhanced transducers at Malin, and in PG\&E's Dynamic System Monitor at Table Mountain. Prony analysis of high speed fault data provided a detailed model for the underlying network resonance signal, and a basis for validating transient performance of a Macrodyne PMUs at the test site. This instrument, which is closely associated with EPRI's FACTS project, provides useful insight into emerging technology for high speed digital transducers. In (Lien et al., 2006), presented a concept of fault-location observability and a new fault-location scheme for transmission networks based on synchronized PMUs. Using the proposed scheme, minimal PMUs are installed in existing power transmission networks so that the fault, if it occurs, can be located correctly in the network. In (Lin et al., 2008), presented a universal fault location technique for N-terminal ( $N \geq 3$ ) transmission lines based on synchronized PMUs. The development of the technique is based on two-terminal fault location technique. The proposed algorithm is different from traditional multi terminal fault location techniques. We apply two-terminal fault location technique to N-terminal transmission lines and propose a novel fault section selector/fault locator. In (Abe et al., 1995), used synchronized three-phase voltages and currents at all terminals. They proposed an algorithm using voltage differentials at terminals to gradually reduce a multi-terminal line to a two-terminal line containing the faulted section. Then, a reactive power-based method was used to locate the fault. Nagasawa et al. (1992) used current differentials at terminals to perform a similar reduction. Their reduction procedure was very complicated and also normalized section impedances when impedances were different. However, this is a source of error. Funabashi et al. (2000) utilized synchronized current inputs from all terminals and developed two different methods to locate the fault.

Sanderson et al. (1993) used both current and voltage data to identify the terminal electrically nearest to the fault. Although the paper reported successful results in identifying the faulted section, the exact fault location on the section was not attempted. Brahma et al. (2005) adopted synchronized voltage measurements to locate the exact fault location. Although the paper reported successful results for locating the fault, the exact source impedance must be considered. Kamwa et al. (2009) proposed a systematic scheme for building compact and transparent fuzzy rulebased classifiers for rapid stability assessment; the classifiers are initialized by large accurate decision trees (DTs). The approach starts by 
selecting strategic monitoring buses where PMUs are placed to capture wide-area response signals in real-time operation. Reference (Lee et al., 2006), presented a new numerical algorithm for fault location estimation and for faults recognition based on the synchronized phasors. The proposed algorithm is based on the synchronized phasor measured from the synchronized PMUs installed at two-terminals of the transmission lines.

\subsection{Application of PMUs for Security/Protection of Power System from Faults}

In Kamwa et al. (2001), a time-frequency-based approach for contingency severity ranking and rapid stability assessment is described. The aim is to classify correctly all single or multiple contingencies that may result in loss of voltage or frequency stability in the first $20 \mathrm{~s}$ following the last disturbing action. We start by selecting a number of strategic monitoring buses where the PMUs are located to capture representative voltage magnitudes and angles during detailed time-domain simulations, which cover special protection systems and on-load tap-changers. In (Corsi et al., 2010), two very promising wide-area voltage protection (V-WAP) solutions, able to face stability and security problems in the transmission grid, are presented. Both require real-time effective risk indicators whose timely computing is a crucial issue. The first method makes use of a voltage instability index based on real-time computing of the Thevenin's equivalent circuit seen by a given high voltage (HV) bus. The innovating algorithm utilized for the real-time adaptive identification of the Thevenin's voltage and impedance equivalent values requires local phasor measurements at fast sampling rate. The unique ability of the second method is mainly because of an effective coordination with a supposed operating wide-area voltage regulation (V-WAR) modern system where the secondary and tertiary voltage regulations (SVR and TVR, respectively) operate according to their hierarchies. Both these complementary controls should be, in principle, operating in a modern power system with relevant advantages with respect to the already existing protections that are mostly related to system components and in some cases to the direct detection of predefined outages in a specific part of the grid: the system protection scheme. Recently, WAP has received a growing consideration because of the increased need for new and more general protecting solutions able to improve somehow the power system security, reliability, management, economy and operation quality by taking advantage of the new technologies, including GPS-synchronized phasor measurements (Rehtanz, 2006). The development of synchronized phasor measurement systems (Phadke, 1993) allows the use of new input signals, local and remote, for power system control. A Synchronized Phasor Measurement System (SPMS) comprehends a set of PMUs, which use a GPS signal to add a time label to measurements, and Phase Data Concentrator, which processes the data sent by the PMUs, originating the synchrophasors. The SPMS allows the measurement of system variables that can give additional information on the non measurable system states, and can be used as input variables for the controllers. Eissa et al. (2010) stated that current differential protection relays are widely applied to the protection of electrical plant due to their simplicity, sensitivity and stability for internal and external faults. The proposed idea has the feature of unit protection relays to protect large power transmission grids based on phasor measurement units. The principle of the protection scheme depends on comparing positive sequence voltage magnitudes at each bus during fault conditions inside a system protection center to detect the nearest bus to the fault. Reference (Borka et al., 2003) presented a concept for local monitoring of the onset of voltage collapse, protective, and emergency control in the presence of voltage-sensitive loads. The onset of voltage collapse point is calculated based on the load characteristics and simulated voltage and current phasors measurements, which are provided by a network of PMUs. If the stability margin is small and the reactive-power reserves are nearly exhausted, then controls to steer the power system away from the critical point will be activated.

In protection relaying schemes (Yu et al., 2006), the digital filter unit plays the essential roles to calculate the accurate phasor. However, while the fault current contains plentiful decaying dc component, the over-reach of distance protection will cause severe problem. This work develops an adaptive mimic phasor estimator to remove the decaying dc oscillation between voltage and current and obtains the accurate apparent impedance. Sun et al. (2007) described an online dynamic security assessment scheme for large-scale interconnected power systems using phasor measurements and decision trees. The scheme builds and periodically updates decision trees offline to decide critical attributes as security indicators. Decision trees provide online security assessment and preventive control guidelines based on real-time measurements of the indicators from PMUs. Detailed security analysis for $\mathrm{N}-\mathrm{k}$ contingencies $(\mathrm{k}=1,2,3,4,5 \ldots)$ in a real-time setting is still a great challenge due to the significant computational burden. This literature takes advantage of PMUs and decision trees (DTs) to develop a real-time security assessment tool to assess four important post-contingency security issues, including voltage magnitude violation (VMV), thermal limit violation (TV), voltage stability (VS) and transient stability (TS). The proposed scheme is tested on the Salt River Project (SRP) power system represented by a series of operating conditions (OCs) during a representative day. The properly trained DTs demonstrate excellent prediction performance. Robustness tests for the offline trained DTs are performed on a group of changed OCs that were not included for training the DTs and the idea of tuning critical system attributes for preventive controls is also presented to improve system security (Diao R., et al., 2010).

\subsection{Application of PMUs in Power Systems with FACTS Controllers}

Varma et al. (2006) stated that sub synchronous resonance (SSR) is a potential problem in power systems having series compensated transmission lines. Flexible AC Transmission Systems (FACTS) Controllers are widely applied to mitigate Sub synchronous Oscillations (SSO). With the advent of WAM technology, it is possible to measure the states of a large interconnected power system with synchronized PMUs. In this literature the concept of using remote signals acquired through PMUs has been proposed to damp SSR. An auxiliary sub synchronous damping controller (SSDC) for a Static VAR Compensator (SVC) using the remote generator speed as the stabilizing signal has been designed to damp sub synchronous oscillations. Zarghami et al. (2010) introduced a new nonlinear control of FACTS controllers for the purpose of damping inter-area oscillations in power systems. FACTS controllers consist of series, shunt, or a combination of series-shunt devices which are interfaced with the bulk power system through injection buses. Controlling the angle of these buses can effectively damp low frequency inter-area oscillations in the system. The proposed control method is based on PMUs, finding an equivalent reduced affine nonlinear system for the network from which the dominant machines are extracted based on dynamic coherency. In (Varma R.K., et al., 2007), presented a novel concept of Static Var Compensator (SVC) damping control using a weighted sum of bus voltage angles of remote generators that are responsible for causing interarea oscillations in power systems. These remote bus voltage angle signals are acquired through PMUs. Inter-area oscillations are essentially caused by the oscillations of the generators. Hence the ideal control signals for damping inter-area oscillations would be the rotor angles of the key generators that participate in inter-area oscillations. It is noted that the voltage angle of a generator bus closely follows the rotor angle of the generator itself. Therefore, intuitively, it seems that the bus voltage angle most closely represents the rotor angle signal as compared to any other 
signal. While it may not be possible to transmit these generator rotor angles to remotely located FACTS Controllers, it may be easier to transmit the generator bus voltage angles utilizing the WAM technology through PMUs (Kamwa et al., 2001).

Yu et al. (2002) presented a new fault location algorithm based on PMUs for series compensated lines. Traditionally, the voltage drop of series device is computed by the device model in the fault locator of series compensated lines, but using this approach errors are induced by the inaccuracy of the series device model or the uncertainty operation mode of the series device. The proposed algorithm does not utilize the series device model and knowledge of the operation mode of the series device to compute the voltage drop during the fault period. Instead, the proposed algorithm uses two-step algorithm, pre-location step and correction step, to calculate the voltage drop and fault location. The proposed technique can be easily applied to any series FACTS compensated line. Zarghami et al. (2010) introduced a new nonlinear control of FACTS controllers for the purpose of damping inter-area oscillations in power systems. FACTS controllers consist of series, shunt, or a combination of series-shunt devices which are interfaced with the bulk power system through injection buses. Controlling the angle of these buses can effectively damp low frequency inter-area oscillations in the system. The proposed control method is based on finding an equivalent reduced affine nonlinear system for the network from which the dominant machines are extracted based on dynamic coherency. A self-correction two-machine equivalent model for the stability control of a FACTS-based transmission system is developed in Yu and Liu (2002). Shaping of the self-correction two machine equivalent models uses only the real-time phasor signals available from the synchronous PMUs. In view of the above, an adaptive distance scheme, which could discriminate its protected zones despite dynamic changes in the series injection levels of the Unified Power Flow Controller (UPFC) and its operating modes, is highly desirable. Such a flexible protection scheme requires the knowledge of the control parameters of the FACTS controllers for zone classification of the distance relays. WAMS can be potentially employed to obtain the control parameters of FACTS controllers in a very short time span, and, therefore, avoid conventional state estimation procedures for arriving at the control settings of the UPFC under a given operating condition, while satisfying a specified control objective (Phadke, 1993). Series compensated power system may lead to a very unusual problem known as Sub-synchronous Resonance (SSR). FACTS controllers are widely applied to mitigate sub-synchronous oscillations. The Static Synchronous Compensator (STATCOM) is a shunt device of the FACTS family using power electronics to control power flow and improve transient stability on power grids. With the advent of WAM technology, it is possible to measure the states of a large interconnected power system with synchronized PMUs (Salemnia et al., 2009). Zarghami et al. (2010) introduced a new nonlinear control of FACTS controllers for the purpose of damping interarea oscillations in power systems. FACTS controllers consist of series, shunt, or a combination of series-shunt devices which are interfaced with the bulk power system through injection buses. Controlling the angle of these buses can effectively damp low frequency interarea oscillations in the system. Chaudhuri et al. (2010) presented on power oscillation damping (POD) control using wide area measurements applied to a single static var compensator (SVC). An equivalent power system model representing key characteristics of the Nordic power system is used in this literature.

\subsection{Application of PMUs for power system state estimation}

Chawasak et al. (2007) presented a new method for an optimal measurement placement of phasor measurement units (PMUs) for power system state estimation. In (Nabil et al., 2009), PMUs are considered as a promising tool for future monitoring, protection and control of power systems. In this literature, a unified approach is proposed in order to determine the optimal number and locations of PMUs to make the system measurement model observable and thereby can be used for power system state estimation. The PMU placement problem is formulated as a binary integer linear programming (BILP), in which the binary decision variables $(0,1)$ determine whether to install a PMU at each bus, while preserving the system observability and lowest system metering economy. A straightforward application of state estimation theory treats phasor measurements of currents and voltages as additional measurements to be appended to traditional measurements now being used in most energy management system (EMS) state estimators (Zhou et al., 2006). In Chakrabarti et al. (2009), a method to assign weights to the measurements obtained through PMUs in a weighted least squares (WLS) state estimation is presented. Chakrabarti et al. (2007, 2009) described the use of two approaches: classical uncertainty propagation theory, and the random fuzzy variables, to compute the PMU measurement uncertainties. The problem of finding optimal PMU locations for power system state estimation is well investigated in the literatures (Nuqui et al., 2005; Chakrabarti et al., 2009). However, the propagation of PMU measurement uncertainty along the transmission lines, and consequently the uncertainties in the estimated states is not adequately addressed so far. Analysis of the uncertainties in the estimated states of a power system is discussed in (Othman and Irving, 2005). Chakrabarti et al. (2009) presented a methodology to include measurements from PMUs as well as conventional measurements in a state estimator. A comprehensive strategy to combine conventional measurements, such as the power flow and power injection measurements, with the direct and pseudo-voltage measurements by the PMUs in a weighted least square (WLS) formulation of the state estimation problem is demonstrated in this literature. Jiang et al. (2008) presented a diakoptic-based distributed state estimation (SE) algorithm suitable for large-scale power systems. In the proposed approach the large-scale power system is divided into a certain number of subsystems by removing tie line measurements. Based on diakoptic theory, the SE problem is then partitioned into a number of sub-problems which are solved for each subsystem using local computational resources. In subsequent steps, the intermediate subsystem SE solutions are sent to a central computer for completing the state estimation process by taking the tie line measurements into consideration. PMUs are used to make each sub-problem solvable and to coordinate the voltage angles of each subsystem SE solution. Extensive research in applying PMU information to improve situational awareness has been conducted since their introduction, including applications in state estimation (Jiang et al., 2007 ; Zhou, 2006; Thorp, 1985), dynamic security assessment (Meliopoulos et al., 2006; Sun et al., 2007; Khatib et al., 2004), and visualization (Zhang et al., 2007; Klump et al., 2005; Lien et al., 2006). Beyond incorporation of PMUs into traditional state estimation, which can include topology estimation (Monticelli et al., 1993), there has been little research into how PMUs can be used to enhance topology information, particularly outside of the local area. Current network topology processors focus on obtaining local system topology information through the use of predominantly local area measurements (Monticelli et al., 2000; Kezunovic et al., 2006; Abur et al., 1995; Lourenço et al., 2006) . However, connectivity information over the wide area is very important for system operations and is a major reason for the existence of the NERC System Data Exchange (SDX) (US-Canada Power System Outage Task Force, Final Report, 2003). Because there is significant value in improving system operators' knowledge of external system line outages, we have developed a method which utilizes PMU data to effect this improvement. In (Zhao et al., 2005), investigated the problem of state estimation in very large power systems, which may contain several control areas. An estimation approach which coordinates locally obtained decentralized estimates while improving bad data processing capability at the area boundaries is presented. In (Rice et al., 2008), state estimation uses measurements to obtain important power system operating information (“states”). 


\subsection{Application of PMUs for power system voltage stability}

Tiwari et al. (2007) treated the operating state of power system changes dynamically due to severe change in system conditions such generation, load or line trip. Such severe disturbances effect voltage phasor, current phasor and system frequency. So, to better monitor the dynamics of large power system, wide area synchronized monitoring of voltage phasor, current phasor and system frequency is vital. For efficient real time monitoring and operation of power system, high resolution based PMUs should be used. PMU can accurately measure node and branch phasors at high sampling rate. Debbie et al. (2010) addressed an artificial neural network (ANN) based method is developed for quickly estimating the long-term voltage stability margin. The investigation presented in the literature showed that node voltage magnitudes and the phase angles are the best predictors of voltage stability margin. Joe et al. (2007) stated that many large interconnected power systems such as the U.S. eastern interconnection and the U.S. western power system are characterized by many power transfer paths or interfaces with high loading. Disruptions of these transfer paths frequently lead to increased loading on neighboring transfer paths, which themselves will become less secure and could cause further disruptions. Xu et al. (2004) presented a selection method for the phasor measurement placement. Taking the transient stability into account, this paper constructs a data platform of PMUs. Sanchai et al. (2008) presented a practical design of fuzzy logic controllers for superconducting magnetic energy storage (SMES) based on a wide area synchronized phasor measurement for enhancing the stability of an interconnected power system. With new systems capable of making synchronised phasor measurements there are possibilities for real-time assessment of the stability of a transient swing in power systems. In the future, online control will be necessary as operating points are pushed closer toward the margin and fast reaction time becomes critical to the survival of the system. A piecewise constant-current load equivalent (PCCLE) technique is developed which utilized synchronized phasor measurements to provide fast-transient stability swing prediction for use with high-speed control (Liu et al., 1995). In (Daniel et al., 2008), the frequency and damping of electromechanical modes offer considerable insight into the dynamic stability properties of a power system. The performance properties of three mode-estimation block-processing algorithms from the perspective of near real-time automated stability assessment are demonstrated and examined.

Corsi and Glauco (2008) proposed a new voltage instability risk indicator based on local phasor measurements at fast sampling rate. The effectiveness of the indicator is analyzed at EHV load and "transit" buses. The risk criterion is based on the real-time computation of the Thevenin equivalent impedance of the classic electrical circuit given by an equivalent generator connected to equivalent load impedance through equivalent connecting impedance. Voltage collapse (Ruisheng et al., 2009) is a critical problem that impacts power system operational security. Timely and accurate assessment of voltage security is necessary to detect post-contingency voltage problems in order to prevent a large scale blackout. This paper presents an online voltage security assessment scheme using synchronized phasor measurements and periodically updated decision trees (DTs). Glavic and Cutsem (2009) addressed the early detection of impending voltage instability from the system states provided by synchronized phasor measurements. Recognizing that voltage instability detection requires assessing a multidimensional system, the method fits a set of algebraic equations to the sampled states, and performs an efficient sensitivity computation in order to identify when a combination of load powers has passed through a maximum. The important effects of over excitation limiters are accounted for. The approach does not require any load model. In (Glavic and Cutsem, 2009), addressed with the early detection of impending voltage instability from the system states provided by synchronized phasor measurements.

\subsection{Application of PMUs for power system Oscillations}

Guoping et al. (2008) presented a new extends the method of Frequency Domain Decomposition (FDD) towards real-time analysis of ambient PMUs measurements in power systems for the purpose of oscillation monitoring. The main idea of FDD is to apply Singular Value Decomposition (SVD) to the power density spectrum matrix. In (Jin et al. 2010), a smart power grid is an integration of the advanced measurement, communication, computer, and control techniques. Among all the state-of-the-art technologies in building a smart power grid, the PMUs is an important and promising one. Nowadays in China, most ultra high and high-voltage buses are all equipped with PMUs. In (Tripathy et al,. 2010), investigated the possibility of using a nonlinear estimator for estimating the internal variables of a synchronous generator, such as the rotor angle, from the data acquired from PMUs. A divide-by-difference filter (DDF) has been used for accurate estimation of the rotor angle of the generator. The proposed rotor angle estimator utilizes the measurements of the terminal voltage, active power output, and field voltage of the generator. Reference (Venkata et al., 2004), has been suggested a direct method to compute the generators' internal dynamical states from the terminal measurements of the voltage, power, and field current of a generator. This method is fast, but the estimated rotor angle may not be quite accurate as it neglects the system dynamics. To find the accurate estimation of phasors by PMUs, during power system oscillations under disturbance, some methods have been proposed in the literatures (Serna, 2003, 2007; Munoz et al., 2008; Serna et al., 2007). Mai et al,. (2010) synchrophasors and frequency estimations play an increasingly important role in power systems. Discrete Fourier transform (DFT) may introduce errors into phasor and frequency estimations under dynamic conditions, such as power oscillation. A dynamic phasor and frequency estimator for PMUs is proposed to improve accuracy by considering dynamic characteristics of power systems expressed as Taylor derivatives. Reference (Brian et al., 2008), introduced the use of regression analysis in the study of small signal stability in large interconnected power systems. Messina et al. (2009) discussed the application of nonstationary time-frequency analysis techniques to identify nonlinear trends and filtering frequency components of the dynamics of large, interconnected power systems. Two different analytical approaches to examine non stationary features are investigated. The first method is based on selective empirical mode decomposition (EMD) of the measured data. The second is based on wavelet shrinkage analysis. Mai et al. (2010) presented a new algorithm for synchrophasor estimation is proposed to improve estimation accuracy under dynamic conditions. The real component of a constantly rotating vector and a low-frequency band-limited vector, which is linearized by Taylor series, is employed to model supplied signals in power systems. Using the present technology, latency associated with remote feedback signals can be determined from the time stamp information at both the PMUs location and the control centre. This study illustrates how this latency could be accounted for in the implementation of a wide-area phasor power oscillation damping controller (POD) (Chaudhuri et al., 2010). Monitoring generator oscillations using Prony analysis is an application that is being increasingly implemented using phasor measurement units (PMUs) data. Most of the existing literature for power system oscillations using Prony method report implementing fixed sampling window that is obtained following a systematic iterative approach taking into account potential disturbances (Peng et al., 2009). In (Korba and Uhlen, 2010), addressed different approaches to detection of critical oscillatory modes. It utilizes fast sampled signals captured with phasor PMUs and a WAM platform. The methods employed here are model-based. 


\subsection{Application of PMUs for electric Distributed power system}

Carta et al. (2008) large-scale distributed measurement systems are the object of several applications and research. The goal of this literature is to develop, by employing GPS receivers, measurement techniques that are suited to the continuous monitoring of the electrical quantities in distribution networks in terms of synchronized phasors.

\subsection{Application of PMUs for Harmonic Measurement in power system}

In Carta et al. (2009), a measurement system, based on high-performance Global Positioning System (GPS) receivers and general-purpose acquisition (DAQ) boards, for the evaluation of the synchronized harmonic phasors in the nodes of an electric distribution network, is presented. To meet the requirements of different fields of application, two measurement procedures have been implemented: One is based on a fixed observation window, whereas, in the other one, the observation interval is a function of the actual power system frequency. In (Carta et al., 2007), the measurement procedures have been extended to the field of harmonic quantities, making them suitable to set up an innovative measurement system that is able to perform evaluations of synchronized harmonic phasors on electric distribution networks. In this literature, further refinements of the procedures, along with new experimental results, are presented. Some works existing in the literature (see, for instance, (Zelingher et al., 2006) proposed GPS-based harmonic measurement systems to determine the harmonic state, specifically for transmission systems. Such systems were developed to address issues of harmonic contamination in the transmission network and the associated possibility of harmonic resonances. PMUs are among the most interesting developments in the field of real-time monitoring of electric power systems (Novosel et al., 2007). In this literature, the implementation of digital procedures that are suitable for the evaluation of the synchronized harmonic phasors in a flexible PMUs based on PXI modular hardware is presented. The results of the experimental tests are shown to characterize the measurement system to evaluate the behavior of the designed instrument under real operating conditions on three-phase electric distribution networks (Carta et al., 2009).

\section{Results and Discussions}

The following Chart gives summary of the paper as:

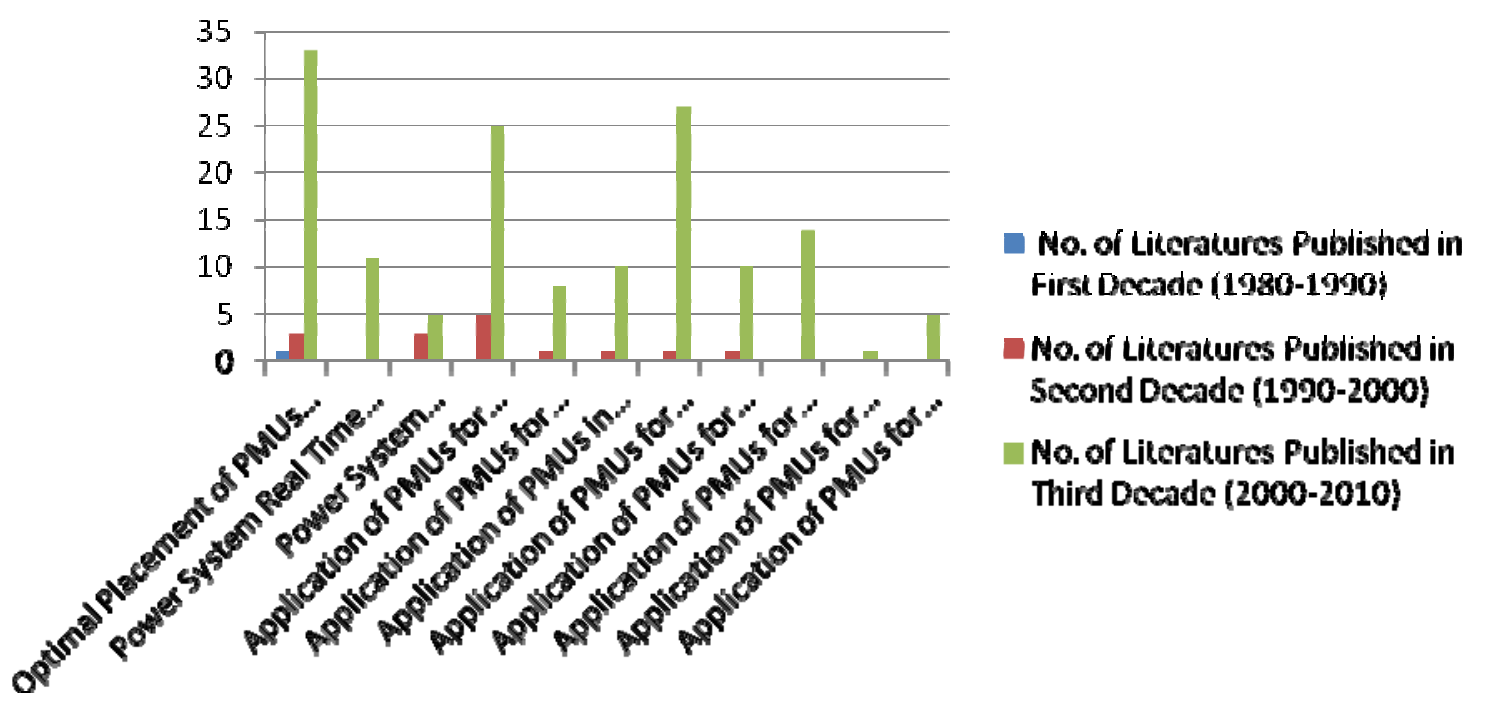

From above chart it is concluded that the 01,03 , and 33 literatures are based on optimal placement of PMUs in power system networks, 00, 00, and 11 literatures are based on power system real time monitoring, 00,03, and 05 literatures are based on power system operation, control, and planning, 00,05,and 25 literatures are based on application of PMUs for fault detection/location of power systems, 00,01, and 08 literatures are based on application of PMUs for security/protection of power system, 00, 01, and 10 literatures are based on application of PMUs in power systems with FACTS controllers, 00,01, and 27 literatures are based on application of PMUs for power system state estimation, 00, 01, and 10 literatures are based on application of PMUs for power system voltage stability, 00, 00, and 14 literatures are based on application of PMUs for power system Oscillations, 00,00, and 01 literatures are based on application of PMUs for electric distributed power system, and 00,00, and 05 literatures are based on application of PMUs for harmonic measurement in power system are no. of literatures published in first decade (19801990), second decade (1990-2000), and third decade (2000-2010) respectively as per chart shown in above. Finally it is concluded that the maximum research work carryout from optimal placement of PMUs in Power System Networks point of view in all thse three decades.

\section{Conclusions}

With the growing interest in PMUs and WAMS throughout the world, it is clear that these systems will be implemented in most major transmission networks. To a large extent the success of this endeavor depends upon adherence to the industry standard governing the PMUs. This paper has been also addressed a survey on Optimal placement of phasor measurement units (PMUs) in power system for enhancement of power system stability such as rotor angle stability, frequency stability, Voltage security, power system oscillations, and voltage stability by 
using different FACTS controllers such as TCSC, SVC, SSSC, STATCOM, UPFC, and IPFC in an integrated power system networks. Also this paper discussed the current status of the research and developments in the field of the applications in PMUs in power systems for enhancement of power system stability such as rotor angle stability, frequency stability, Voltage security, power system oscillations, and voltage stability enhancement by using different FACTS controllers in an integrated power system networks. Authors strongly believe that this survey article will be very much useful to the researchers for finding out the relevant references in the field of the applications of PMUs in power systems for enhancement of power system stability by using different FACTS controllers in an integrated power system network.

\section{Acknowledgment}

The authors would like to thanks Dr. S. C. Srivastava, Indian Institute of Technology, Kanpur, U.P., India, and Dr. N. P.Pandhy, Indian Institute of Technology, Roorkee, UTTARAKAND, India, and Dr. Deependra Singh, Kamla Nehru Institute of Technology, Sultanpur, U.P., India, for their valuables suggestions regarding different application of PMUs in power system environments.

\section{References}

Abe M., Otsuzuki N., Emura T., and Takeuchi M.,1995, "Development of a new fault location system for multi-terminal single transmission lines,” IEEE Trans. Power Del., vol. 10, no. 1, pp. 159-168.

Abur A., Kim H., and Çelik M., 1995, “Identifying the unknown circuit breaker statuses in power networks,” IEEE Trans. Power Syst., vol. 10, no. 4, pp. 2029-2037.

Almutairi A. M., and Milanovi J. V., 2009, “Comparison of Different Methods for Optimal Placement of PMUs,” Paper accepted for presentation at 2009 IEEE Bucharest Power Tech Conference, June 28th - July 2nd, Bucharest, Romania.

Aminifar F., Lucas C., Khodaei A., and Fotuhi-Firuzabad M., 2009 "Optimal Placement of Phasor Measurement Units Using Immunity Genetic Algorithm,” IEEE Trans on Power Delivery, Vol. 24, No. 3, pp. 1014-1020.

Aminifar F., Bagheri-Shouraki S., Fotuhi-Firuzabad M., and Shahidehpour M., 2010, "Reliability Modeling of PMUs Using Fuzzy Sets,” IEEE Trans. On Power Delivery, Vol. 25, No. 4, pp. 2384-2391.

Aminifar F., Khodaei A., Fotuhi-Firuzabad M., and Mohammad S., 2010 "Contingency-Constrained PMU Placement in Power Networks," IEEE Trans. On Power Systems, Vol. 25, No. 1.

Aranya C., Chow J.H., and Salazar A., 2009, "Interarea Model Estimation for Radial Power System Transfer Paths With Intermediate Voltage Control Using Synchronized Phasor Measurements,” IEEE Trans. On Power Systems, Vol. 24, No. 3.

Baldwin T. L., Mili L., M B. Jr, and Adapa R., 1993 "Power system observability with minimal phasor measurement placement," IEEE Trans. on Power Syst., vol. 8, no. 2, pp. 707-715.

Bertsch J., Carnal C., Karlson D., McDaniel J., and Vu K., 2005 “Wide-area protection and power system utilization,” Proc. IEEE, vol. 93, no. 5, pp. 997-1000.

Bhargava B., 1999 "Synchronized phasor measurement sy.stem project at Southern California Edison Co.," in Proceedings of the 1999 IEEE/PES Summer Meeting, Edmonton, Alberta, Canada, July 18-22, 1999, pp. 16-22.

Borka M., and Begovic M., 2003, "Voltage-Stability Protection and Control Using a Wide-Area Network of Phasor Measurements,” IEEE Trans. On power Systems, Vol. 18, No.1, pp.674-679.

Brahma S. M., 2005, "Fault location scheme for a multi-terminal transmission line using synchronized voltage measurements," IEEE Trans. Power Del., vol. 20, no. 2, pp. 1325-1331.

Brahma S. M., 2007, "Iterative Fault Location Scheme for a Transmission Line Using Synchronized Phasor Measurements," Volume 8, Issue 6.

Brahma S., Girgis A., 2004, Fault Location on a Transmission Line Using Synchronized Voltage Measurements, IEEE Trans. Power Delivery, 19(4), 2004, 1619-1622.

Brian A. A., Udaya D. A., Bathiya J., and Punya W., 2008, “Accurate Prediction of Damping in Large Interconnected Power Systems with the Aid of Regression Analysis,” IEEE Trans. On Power Systems, Vol. 23, No. 3, pp. 347-354.

Chakrabarti S., and Kyriakides E., 2009,“PMU Measurement Uncertainty Considerations in WLS State Estimation,” IEEE Trans. On Power Systems, Vol. 24, No. 2, pp. 1062-1071, May 2009.

Chakrabarti S., Kyriakides E., Gustavo V., and Terzija V., 2009, "State Estimation Including Synchronized Measurements," This paper is accepted for presentation at 2009 IEEE Bucharest Power Tech Conference, June $28^{\text {th }}$ - July 2nd, Bucharest, Romania.

Chakrabarti S., and Kyriakides E., 2007 “Optimal placement of phasor measurement units for state estimation,” in Proc. IASTED Int. Conf. Power Energy Syst. EuroPES, Palma de Mallorca, Spain, pp. 1-6.

Chakrabarti S., Eliades D., Kyriakides E., and Albu M., 2007, "Measurement uncertainty considerations in optimal sensor deployment for state estimation,” in Proc. IEEE Int. Symp. WISP, Madrid, Spain, pp. 1-6.

Chakrabarti S., and Kyriakides E., 2008 "Optimal Placement of Phasor Measurement Units for Power System Observability," IEEE Trans on Power Systems, Vol. 23, No. 3, pp. 1433-1440.

Chakrabarti S., Kyriakides E., and Albu M., 2009 "Uncertainty in Power System State Variables Obtained Through Synchronized Measurements,” IEEE Trans. On Instrumentation and Measurement, Vol. 58, No. 8, pp. 2452-2458.

Chakrabarti S., Kyriakides E., and Eliades D.G., 2009, "Placement of synchronized measurements for power system observability," IEEE Trans. Power Del., vol. 24, no. 1, pp. 12-19.

Carta A., Locci N., and Carlo M., 2009 "A PMU for the Measurement of Synchronizedm Harmonic Phasors in Three-Phase Distribution Networks,” IEEE Trans. On Instrumentation and measurement, Vol. 58, No. 10, pp. 2546-2555. 
Carta A., Locci N., and Carlo M., 2007, “GPS-based system for the measurement of synchronized harmonic phasors,” in Proc. IEEE IMTC, Warsaw, Poland, May 1-3, pp. 1-5.

Carta A., Locci N., Carlo M., and Sara S., 2008, "A Flexible GPS-Based System for Synchronized Phasor Measurement in Electric Distribution Networks,” IEEE Trans. On Instrumentation and Measurement, Vol. 57, No. 11, pp.2450-2456.

Carta A., Locci N., and Carlo M., 2009, “GPS-Based System for the Measurement of Synchronized Harmonic Phasors,” IEEE Trans on Instrumentation and Measurement, Vol. 58, No. 3, pp. 897-906.

Chaudhuri N.R., Domahidi A., Majumder R., Chaudhuri B., Korba P., Ray S., Uhlen K., 2010, "Wide-area power oscillation damping control in Nordic equivalent system,” IET Gener. Transm. Distrib., Vol. 4, Iss. 10, pp. 1139-1150.

Chaudhuri N.R., Chaudhuri B., Ray S., and Majumder R., 2010, "Wide-area phasor power oscillation damping controller: a new approach to handling time-varying signal latency,” IET Gener. Transm. Distrib., 2010, Vol. 4, Issue. 5, pp. 620-630.

Chawasak R., Suttichai P., Sermsak U., and Neville R. W., 2007 "An Optimal PMU Placement Method against Measurement Loss and Branch Outage,” IEEE Trans. On Power Delivery, Vol. 22, No. 1, pp. 101-107.

Chen J., and Abur A., 2006 "Placement of PMUs to enable bad data detection in state estimation,” IEEE Trans. Power Syst., vol. 21, no. 4, pp.1608-1615.

Chen J., Li F., Fan L., Zhang P., 2008, "Review of PMU-based Online Applications for Dynamic Simulation, Fault Detection, and Cascading Failure Prevention,” Proceedings of the 8th WSEAS International Conference on Electric Power Systems, High Voltages, Electric Machines (POWER '08), 2008.

Chen J., and Abur A., 2008 “Enhanced Topology Error Processing via Optimal Measurement Design,” IEEE Trans. On Power Systems, Vol. 23, No. 3, pp. 845-852.

Cho K. S., Shin J.R., and Hyun S.H., 2001 “Optimal placement of phasor measurement units with GPS receiver," in Proc. IEEE Power Engineering Society Winter Meeting, Jan.-Feb. 2001, vol. 1, pp. 258-262.

Chuang C.L., Jiang J.A.,Wang Y.C., Chen C.P., and Hsiao Y.T.,2007, "An Adaptive PMU-based Fault Location Estimation System with a Fault-Tolerance and Load-Balancing Communication Network,” Power Tech, 2007 IEEE, Lausanne, pp. 11971202.

Corsi S., 2009, “Wide area voltage regulation and protection,” Proc. Power Tech 09, Bucharest, June-July 2009.

Corsi S., 2010, “Wide Area Voltage Protection,” IET Gener. Transm. Distrib., 2010, Vol. 4, Iss. 10, pp. 1164-1179.

Corsi S., and Glauco N. T., 2008, “A Real-Time Voltage Instability Identification Algorithm Based on Local Phasor Measurements," IEEE Trans. On Power Systems, Vol. 23, No. 3, pp. 456-463.

Daniel J. T., John W. P., Ning Z., John F. H., and Manu P., 2008, "Performance of Three Mode-Meter Block-Processing Algorithms for Automated Dynamic Stability Assessment,” IEEE Trans. On Power Systems, Vol. 23, No. 2, pp. 678-684.

Debbie Q. Zhou, U. D. Annakkage, and Athula D. Rajapakse, 2010, "Online Monitoring of Voltage Stability Margin Using an Artificial Neural Network,” IEEE Trans. On Power Systems, Vol. 25, No. 3, pp. 453-459.

Diao R., Vittal V., and Naim L., 2010, "Design of a Real-Time Security Assessment Tool for Situational Awareness Enhancement in Modern Power Systems,” IEEE Trans. On Power Systems, Vol. 25, No. 2.

Djuric M., Radojevic Z., Terzija V., 1998, Distance protection and fault location utilizing only phase current phasors, IEEE Trans. Power Delivery, 13(4), 1998, pp.1020-1026.

Donolo M. A., and Centeno V. A., 2005, “A Fast Quality Assessment Algorithm for Phasor Measurements,” IEEE Trans. On Power Delivery, Vol. 20, No. 4, pp. 2407-2413.

Eissa M.M., Masoud M.E., and Elanwar M.M.M., 2010, "A Novel Back Up Wide Area Protection Technique for Power Transmission Grids Using Phasor Measurement Unit,” IEEE Trans on Power Delivery, Vol. 25, No. 1, pp. 270-278.

Emami R., and Abur A., 2010, "Robust Measurement Design by Placing Synchronized Phasor Measurements on Network Branches," IEEE Trans on Power Systems, Vol. 25, No. 1, pp.768-777.

EPRI Final Rep., 1997 "Assessment of Applications and Benefits of Phasor Measurement Technology in Power Systems,” GE Power Syst. Eng.,

Fan D., and Centeno V., 2007, “Phasor-Based Synchronized Frequency Measurement in Power Systems,” IEEE Trans. On Power Delivery, Vol. 22, No. 4, pp. 2010-2016.

Faucon O., and Dousset L., 1997 “Coordinated defence plan projects against transient instabilities,” IEEE Computer Applications in Power, vol. 10, no. 3, pp. 22-26.

Ferrero A., and Salicone S., 2004, "The random fuzzy variables: A new approach to the expression of uncertainty in measurement,” IEEE Trans. Instrum. Meas., vol. 53, no. 5, pp. 1370-1377.

Ferrero A., and Salicone S., 2006, "Fully comprehensive mathematical approach to the expression of uncertainty in measurement," IEEE Trans. Instrum. Meas., vol. 55, no. 3, pp. 706-712.

Funabashi T., Otoguro H., Mizuma Y., Dube L., and Ametani A.,2000, "Digital fault location algorithm for parallel double-circuit multiterminal transmission lines,” IEEE Trans. Power Del., vol. 15, no. 2, pp. 531-537.

Girgis A., Hart D., Peterson W., 1992, A new fault location technique for two- and three-terminal lines, IEEE Trans. Power Delivery, 7(1), 1992, 98-107.

Glavic M., and Cutsem T.V., 2009, "Wide-Area Detection of Voltage Instability from Synchronized Phasor Measurements. Part I: Principle,” IEEE Trans. On Power Systems, Vol. 24, No. 3, pp. 1408-1416.

Glavic M., and Cutsem T.V., 2009, "Wide-Area Detection of Voltage Instability from Synchronized Phasor Measurements. Part II: Simulation Results,” IEEE Trans on Power Systems, Vol. 24, No. 3, pp. 1417-1425. 
Gopalakrishnan A., Hamai D., Kezunovic M., McKenna S., 2000, Fault location using the distributed parameter transmission line model, IEEE Trans. Power Delivery, 15(4), 2000, 1169-1174.

Gou B., 2008 “Optimal Placement of PMUs by Integer Linear Programming,” IEEE Trans. on Power Systems, Vol. 23, No. 3, pp. 1525-1532, August 2008.

Gou B., 2008, “Generalized Integer Linear Programming Formulation for Optimal PMU Placement,” IEEE Trans. On Power Systems, Vol. 23, No. 3, pp. 1099-1104.

Guoping L., and Mani V.V., 2008, "Oscillation Monitoring from Ambient PMU Measurements by Frequency Domain Decomposition,” Circuits and Systems, 2008. ISCAS 2008. IEEE International Symposium on, pp. 2821-2824, Seattle, WA, pp.18-21.

Hashiguchi, T., Yoshimoto, M., Mitani, Y., Saeki, O., Tsuji, K., Hojo, M., Ukai, H., Toyoda, J., and Matsushita, A., 2004, "Analysis of oscillation characteristics followed by power system disturbance based on multiple synchronized phasor measurements,” Proc. Int. Conf. Electrical Engineering.

Hauer J. F., Trudnowski D., Rogers G., Mittelstadt B., Litzenberger W., and Johnson J., 1997 "Keeping an eye on power system dynamics,” IEEE Comput. Appl. Power, vol. 10, pp. 50-54.

Hauer J.F., 1991 "Application of Prony analysis to the determination of modal content and equivalent models for measured power system response,” IEEE Trans. Power Syst., vol. 6, pp. 1062-1068.

Hauer J. F., 1996, "Validation Of Phasor Calculations In The Macrodyne PMU For California-Oregon Transmission Project Tests Of March 1993,” IEEE Transactions on Power Delivery, Vol. 11, No. 3.

Heydt G. T., Lie C. C., Phadke A. G., and Vital V., 2001 “Solutions for the crisis in electric power supply,” IEEE Comput. Appl. Power Mag., vol.14, no. 3, pp. 22-30.

ISO-IEC-OIML-BIPM, 1992, Guide to the Expression of Uncertainty in Measurement, 1992.

JCGM YYY: 2006, Evaluation of measurement data-Supplement 1 to the 'guide to the expression of uncertainty in measurement-Propagation of distributions using a Monte Carlo method.

Jiang J.A., Yang J.Z., Lin Y.H., Liu C.W., and Chen J.,2000, "An adaptive PMU based fault detection/location technique for transmission lines-part I: Theory and algorithms," IEEE Trans. Power Del., vol. 15, no. 2, pp. 486-493, April 2000.

Jiang J.A., Lin Y.H., Yang J.Z., Too T.M, and Liu C.W., 2000, "An adaptive PMU based fault detection/location technique for transmission lines-part II: PMU implementation and performance evaluation," IEEE Trans. Power Del., vol. 15, no. 4, pp. 11361146.

Jiang J.A., Lin Y.H., Yang J.Z., Too T.M, and Liu C.W., 2000, “An Adaptive PMU Based Fault Detection/Location Technique for Transmission Lines-Part II: PMU Implementation and Performance Evaluation,” IEEE Trans. On Power Delivery, Vol. 15, No. 4, pp 486-493.

Jiang W., Vittal V., and Heydt G.T., 2008, “Diakoptic State Estimation Using Phasor Measurement Units,” IEEE Trans. On Power Systems, Vol. 23, No. 4, pp. 1580-1589.

Jiang W., Vittal V., and Heydt G.T. , 2007, “A distributed state estimator utilizing synchronized phasor measurements,” IEEE Trans. Power Syst., vol. 22, pt. 2, pp. 563-571.

Jiao L., and Wang L., 2000 “A novel genetic algorithm based on immunity,” IEEE Trans Syst., Man, Cybern., vol. 30, no. 5, pp. 552-561.

Jin M., Zhang P., Fu H.J., Bo B., and Dong Z.Y., 2010, “Application of Phasor Measurement Unit on Locating Disturbance Source for Low Frequency Oscillation,” IEEE Trans. On Smart Grid, Vol. 1, No. 3, pp 340-346.

Joana R., and Preben J., 2006, “Synchronized Phasor Measurements of a Power System Event in Eastern Denmark,” IEEE Trans. On Power Systems, Vol. 21, No. 1, pp.234-243.

Joe H. C., Aranya C., Murat A., Bharat B., and Salazar A., 2007, "Synchronized Phasor Data Based Energy Function Analysis of Dominant Power Transfer Paths in Large Power Systems,” IEEE Trans on. Power Systems, Vol. 22, No. 2, pp. 727-734, May 2007.

John F. H., William A. M., Kenneth E. M.,, James W. B., Harry L., John W. P., and Daniel J. T.,2009, "Use of the WECC WAMS in Wide-Area Probing Tests for Validation of System Performance and Modeling,” IEEE Trans on Power Systems, Vol. 24, No. 1, pp.786-794.

Kakimoto, N., Sugumi, M., Makino, T., and Tomiyama, K., 2006, "Monitoring of Interarea oscillation mode by synchronized phasor measurement,” IEEE Transactions on Power Systems, vol. 21, no. 1, pp. 260-268.

Kamwa I., Pradhan A.K., and Joós G., 2007, “Automatic Segmentation of Large Power Systems into Fuzzy Coherent Areas for Dynamic Vulnerability Assessment,” IEEE Trans. On Power Systems, Vol. 22, No. 4, pp. 457-464.

Kamwa I., Robert G., and Loud L., 2001, "Time-Varying Contingency Screening for Dynamic Security Assessment Using Intelligent-Systems Techniques,” IEEE Trans. On Power Systems, Vol. 16, No. 3, pp. 526-536.

Kamwa I., Pradhan A. K., Joos G., and Samantaray S.R., 2009, "Fuzzy Partitioning of a Real Power System for Dynamic Vulnerability Assessment,” IEEE Trans. On Power Systems, Vol. 24, No. 3.

Kamwa I., Samantaray S.R., and Joos G., 2009, "Development of Rule-Based Classifiers for Rapid Stability Assessment of WideArea Post-Disturbance Records,” IEEE Trans. On Power Systems, Vol. 24, No. 1, pp. 258-270.

Kamwa I., Robert G., and Hébert Y., 2001, “Wide-Area Measurement Based Stabilizing Control of Large Power Systems-A Decentralized/Hierarchical Approach,” IEEE Trans on Power Systems, Vol. 16, No. 1, pp.136-153. 
Kerdchuen T., and Ongsakul W., 2008 "Optimal Placement of PMU and RTU by Hybrid Genetic Algorithm and Simulated Annealing for Multiarea Power System State Estimation,” GMSARN International Conference on Sustainable Development: Issues and Prospects for GMS, 12-14 Nov. 2008.

Kezunovic M., 2006, “Monitoring of power system topology in real-time,” in Proc. 39th Hawaii Int. Conf. System Sciences.

Khatib A.K., Nuqui R.F., Ingram M.R., and Phadke A.G., 2004, "Real-time estimation of security from voltage collapse using synchronized phasor measurements,” in Proc. IEEE Power Eng. Soc. General Meeting, Jun. 2004, vol. 1, pp. 582-588.

Klump R., Wilson R.E., and Martin K.E., 2005, "Visualizing real-time security threats are using hybrid SCADA/PMU measurement displays,” in Proc. 38th Hawaii Int. Conf. System Sciences.

Kosterev D. N., and Estergalyos J., and Stigers C. A., 1998“Feasibility study of using synchronized phasor measurements for generator dropping controls in the colstrip system,” IEEE Trans. on Power Systems, vol. 13, no. 3, pp. 755-762.

Kosterev D. N., Taylor C. W., and Mittelstadt W.A., 1999 "Model validation for the August 10, 1996 WSCC system outage," IEEE Trans. Power Syst., vol. 14, pp. 967-979.

Korba P., and Uhlen K., 2010, "Wide-area monitoring of electromechanical oscillations in the Nordic power system: practical experience,” IET Gener. Transm. Distrib., Vol. 4, Iss. 10, pp. 1116-1126.

Lee C.J., Park J.B., Shin J.R., and, Zoran R., 2006, "Two Terminals Numerical Algorithm for Distance Protection, Fault Location and Acing Faults Recognition Based on Synchronized Phasors,” Journal of Electrical Engineering \& Technology, Vol. 1, No. 1, pp. 35-41.

Lien K.L., Liu C.W., Yu C.S., and Jiang J.A., 2006, "Transmission Network Fault Location Observability with Minimal PMU Placement,” IEEE Trans on Power Delivery, Vol. 21, No. 3.

Lien S.C., and Yuan J.B., 2006, "Visualization of large-scale power system operations uses phasor measurements," in Proc. Int. Conf. Power Systems Technology.

Lin Y. H., Liu C. W., and Chen C.S., 2004, “A New PMU-Based Fault Detection/Location Technique for Transmission Lines With Consideration of Arcing Fault Discrimination—Part I: Theory and Algorithms,” IEEE Trans. On Power Delivery, Vol. 19, No. 4, pp. 1587-1593.

Liu C.W., and Thorp J., 1995, "Application of synchronised phasor measurements to real-time transient stability prediction," IEE Proc.-Gener. Trunsm. Disirih., Vol. 142. No. 4, pp.345-356

Liu C.W., Lien K.P., Chen C.S., and Jiang J.A.2008, "A Universal Fault Location Technique for N-Terminal $(N \geq 3)$ Transmission Lines,” IEEE Trans on Power Delivery, Vol. 23, No. 3. pp. 2354-2362.

Lourenço E., Costa A., Clements K., and Cernev R., 2006, "A topology error identification method directly based on collinearity tests,” IEEE Trans. Power Syst., vol. 21, no. 4, pp. 1920-1929.

Madtharad C., Premrudeepreechacharn S., Watson N. R., and Saenrak D., 2003 "Measurement placement method for power system state estimation: part I,” in Proc. of IEEE Power Engineering Society General Meeting, vol. 3, pp. 1632-1635.

Mai R.K., He Z.Y., Fu L., He W., Bo Z.Q., 2010, “Dynamic phasor and frequency estimator for phasor measurement unit,” IET Gener. Transm. Distrib., Vol. 4, Iss. 1, pp. 73-83.

Mai R.K., He Z.Y., Fu L., Kirby B., and Bo Z. Q., 2010, “A Dynamic Synchrophasor Estimation Algorithm for Online Application,” IEEE Trans. On Power Delivery, Vol. 25, No. 2, April 2010.

Mao X. M., Zhang Y., Guan L., Wu X. C. and Zhang N., 2008 "Improving power system dynamic performance using wide-area high-voltage direct current damping control,” IET Gener. Transm. Distrib., 2, (2), pp. 245-251.

Marcos A. D., Virgilio A. C., and Liu Y., 2006, “Improving Frequency Measurements Switching Loads,” IEEE Trans. On Power Delivery, Vol. 21, No. 4.

Marın F. J., Garcia-Lagos F., J.G., and Sandoval F., 2003 "Genetic algorithms for optimal placement of phasor measurement units in electric networks,” Electron. Lett. vol. 39, no. 19, pp. 1403-1405.

Meliopoulos A.P.S., Cokkinides G.J., Wasynczuk O., Coyle E., Hoffmann C., Rotaru C.N., Downar T.,Tsoukalas L., and Gao R., 2006, "PMU data characterization and application to stability monitoring," in Proc. 2006 IEEE Power Eng. Soc. Power Systems Conf. Expo., pp. 151-158.

Milosevic B., and Begovic M., 2003 “Nondominated sorting genetic algorithm for optimal phasor measurement placement,” IEEE Trans. on Power Syst., vol. 18, no. 1, pp. 69-75.

Messina A. R., and Vittal V.,2007, "Extraction of Dynamic Patterns From Wide-Area Measurements Using Empirical Orthogonal Functions,” IEEE Trans. On Power Systems, Vol. 22, No. 2, pp 456-462.

Messina A.R., Vittal V., Heydt G.T., and Browne T.J., 2009, "Nonstationary Approaches to Trend Identification and Denoising of Measured Power System Oscillations,” IEEE Trans. On Power Systems, Vol. 24, No. 4, pp.678-685.

Missout G. and Lafleur Y.,1993 "Phasor monitoring systems at Hydro-Québec: Development and output since 1981,” in 1993 IEEE/PES Summer Meeting, Panel Session on Applications and Experience in Power System Monitoring with Phasor Measurements.

Mittelstadt W.A., Krause P. E., Overholt P. N., Hauer J.F.,Wilson R. E, and Rizy D. T., 1995 “The DOE wide area measurement system (WAMS) project-Demonstration of dynamic information technology for future power system," in Fault and Disturbance Analysis \& Precise Measurements in Power Systems, Session 4, Arlington, VA, Nov., pp. 8-10.

Monticelli A., 1993, "Modeling circuit breakers in weighted least squares state estimation,” IEEE Trans. Power Syst., vol. 8, no. 3, pp. 1143-1149. 
Monticelli A., 2000, “Electric power system state estimation,” Proc. IEEE, vol. 88, no. 2, pp. 262-282.

Munoz A.T., and Serna J.A.D.L.O., 2008, “Shanks' method for dynamic phasor estimation,” IEEE Trans. Instrum. Meas., vol. 57, no. 4, pp. 813-819.

Nabil H. Abbasy, and Hanafy M. I., 2009, "A Unified Approach for the Optimal PMU Location for Power System State Estimation,” IEEE Trans on Power Systems, Vol. 24, No. 2, pp. 806-813.

Nagasawa T., Abe M., Otsuzuki N., Emura T., Jikihara Y., and Takeuchi M.,1992, "Development of a new fault location algorithm for multiterminal two parallel transmission lines,” IEEE Trans. Power Del., vol. 7, no. 3, pp. 1516-1532.

Nourizadeh S., Ranjbar A. M., Mahmoud R. P., and Morteza S., 2010, "Standing Phase Angle Reduction Based on a Wide Area Monitoring System Using Genetic Algorithm,” International Journal of Emerging Electric Power Systems, Volume 11, Issue 3, pp.345-357.

Novosel D., Madani V.,Bhargava B., Vu K, and Cole J., 2008 “Dawn of the grid synchronization,” IEEE Power Energy Mag., vol. 6, no. 1, pp. 49-60.

Novosel D., Vu K., Centeno V., Skok S., and Begovic M., 2007, "Benefits of synchronized-measurement technology for power-grid applications,” in Proc. 40th Hawaii Int. Conf. Syst. Sci., pp. 118-125..

Nuqui R. F., and Phadke A. G., 2005 "Phasor measurement unit placement techniques for complete and incomplete observability," IEEE Trans. Power Del., vol. 20, no. 4, pp. 2381, 2388.

Othman A.K.A., and Irving M.R., 2005, “Uncertainty modeling in power system state estimation,” Proc. Inst. Elect. Eng., Gen., Transm., Distrib., vol. 152, no. 2, pp. 233-239.

Othman A.K.A., and Irving M.R., 2005, "A comparative study of two methods for uncertainty analysis in power system state estimation,” IEEE Trans. Power Syst., vol. 20, no. 2, pp. 1181-1182.

Pereira R. A. F., Silva L.G. W., and Mantovani J. R. S., 2004, "PMUs Optimized Allocation Using a Tabu Search Algorithm for Fault Location in Electric Power Distribution System,” 2004 IEEE PES Transmission \& Distribution Conference \& Exposition: Latin America.

Pereira C., Zanetta L. Jr., 2004, Fault location in transmission lines using one terminal post fault voltage data, IEEE Trans. Power Delivery, 19(2), 2004, pp. 570-575.

Peng J., Sun Y., and Wang H.F. ,2006 “Optimal PMU placement for full network observability using Tabu search algorithm," Elec. Power Syst. Res., vol. 28, no. 4, pp. 223-231.

Peng J.C.H., and Nair N.K.C., 2009, “Adaptive sampling scheme for monitoring oscillations using Prony analysis,” IET Gener. Transm. Distrib., Vol. 3, Iss. 12, pp. 1052-1060.

Pereira L., Undrill J., Kosterev D., Davies D., and Patterson S., 2003 “A new thermal governor modeling approach in the WECC,” IEEE Trans. Power Syst., vol. 18, pp. 819-829.

Phadke A.G., 1993, "Synchronized phasor measurements in power systems,” IEEE Computer Applications in Power, 6(2), pp.1015.

Phadke A.G., Pickett B., Adamiak M., Begovic M., Benmouyal G., Burnett R.O. Jr.,Cease T.W., Goossens J.,Hansen D.J., Kezunovic M., Mankoff L.L., McLaren P.G., Michel G., Murphy R.J., Nordstrom J., Sachdev M.S., Smith H.S., Thorp J.S., Trotignon M., Wang T.C., and Xavier M.A. 1994, "Synchronized sampling and phasor measurements for relaying and control," IEEE Trans. Power Del., vol. 9, no. 1, pp. 442-452.

Phadke A. G., and Thorp J. S., 2008 "Synchronized Phasor Measurements and Their Applications”, New York, Springer.

Phadke A.G., and Kasztenny B., 2009 "Synchronized Phasor and Frequency Measurement under Transient Conditions," IEEE Trans. On Power Delivery, Vol. 24, No. 1, pp. 89-95.

Phadke A. G., Thorp J. S., and Adamiak M. G., 1983 "New measurement techniques for tracking voltage phasors, local system frequency, and rate of change of frequency,” IEEE Trans. Power App. Syst., vol. 102, pp. 1025-1038.

Rehtanz C., 2006, "Wide area monitoring and control for transmission capability enhancement” Cigre WG C4.601, Technical Brochure, 2006.

Revision of IEEE Std 1344, 1995 “IEEE Standard for Synchrophasors for Power Systems,” IEEE Standard C37.118-2005.

Rice M.J., and Heydt G.T., 2008, “The Measurement Outage Table and State Estimation,” IEEE Trans on Power Systems, Vol. 23, No. 2, May 2008.

Ruisheng D., Kai S., Vittal V., Robert J. O.K., Michael R. R., Navin B., Dwayne S., and Sanjoy K. S., 2009, "Decision Tree-Based Online Voltage Security Assessment Using PMU Measurements,” IEEE Trans on Power Systems, Vol. 24, No. 2, pp.459-466.

Salemnia A., Khederzadeh M., and Ghorbani A.,2009, "Mitigation of Subsynchronous Oscillations by 48-Pulse VSC STATCOM Using Remote Signal,” 2009 IEEE, Bucharest Power Tech Conference, $28^{\text {th }}$ June-2nd July,Bucharest Romania.

Sanchai D., Komsan H., Masayuki W., Mitani Y., and Ngamroo I., 2008, "A Practical Design of a Fuzzy SMES Controller Based on Synchronized Phasor Measurement for Interconnected Power Systems,” International Journal of Emerging Electric Power Systems, Volume 9, Issue 3, pp.567-572.

Sanderson J.V.H., Santana R.G.R., and Fakri B.A., 1993, "Improved directional comparison based algorithm for protection of multiterminal transmission lines,” in Proc. 5th Int. Conf. Developments Power Syst. Protection, 1993, vol. 368, pp. $153-156$.

Samuelsson O., 2000, "Wide Area Measurements of Power System Dynamics-the North American WAMS Project and Its Applicability to the Nordic Countries,” ELFORSK, pp. 99-50.

Schulz R. P., and Laios B. B., 1997“Triggering tradeoffs for recording dynamics,” IEEE Computer Applications in Power, vol. 10, no. 2, pp. 43-49. 
Serna J.A.D.L.O., 2003, “Improving phasor measurements under power system oscillations,” IEEE Trans. Power Syst., vol. 18, no. 1, pp. 160-166.

Serna J.A.D.L.O, 2007, “Dynamic phasor estimates for power system oscillations,” IEEE Trans. Instrum. Meas., vol. 56, no. 5, pp. 1648-1657.

Serna J.A.D.L.O., 2007, "Reducing the error in phasor estimates from phasorlets in fault voltage and current signals,” IEEE Trans. Instrum. Meas., vol. 56, no. 3, pp. 856-866.

Sodhi R., and Srivastava S. C. 2008, "Optimal PMU Placement to Ensure Observability of Power System,” Fifteenth National Power Systems Conference (NPSC), IIT Bombay, December 2008.

Stewart E. Stanton C. S., Kenneth M., Jerry N., 1995, "Application of Phasor Measurents and Partial Energy Analysis in Stabilizing Large Distribance,” IEEE Transactions on Power Systems, Vol. 10, No. 1 pp.476-484.

Sun K., Siddharth L., Vittal V., Kolluri V.S., and Mandal S.,2007, "An Online Dynamic Security Assessment Scheme Using Phasor Measurements and Decision Trees,” IEEE Trans. On Power Systems, Vol. 22, No. 4,pp 1935-1943.

Serna J.A.D.L.O., 2003, “Improving phasor measurements under power system oscillations,” IEEE Trans. Power Syst., vol. 18, no. 1, pp. 160-166.

Serna J.A.D.L.O, 2007, “Dynamic phasor estimates for power system oscillations,” IEEE Trans. Instrum. Meas., vol. 56, no. 5, pp. 1648-1657.

Serna J.A.D.L.O., 2007, "Reducing the error in phasor estimates from phasorlets in fault voltage and current signals,” IEEE Trans. Instrum. Meas., vol. 56, no. 3, pp. 856-866.

Tate J. E., and Overbye T. J., 2008 “Line Outage Detection Using Phasor Angle Measurements,” IEEE Trans. On Power Systems, Vol. 23, No. 4, pp. 1644-1652.

Tawfik M., Morcos M., 2001, ANN-based techniques for estimating fault location on transmission lines using Prony method, IEEE Trans. Power Delivery, 16(2), 2001, pp. 219-224.

Thorp J.S., Phadke A.G., and Karimi K.J., 1985, “Real time voltage-phasor measurements for static state estimation,” IEEE Trans. Power App. Syst., vol. PAS-104, pp. 3098-3106, Nov. 1985.

Tiwari A., and Ajjarapu V., 2007, "Event Identification and Contingency Assessment for Voltage Stability via PMU," Power Symposium, 2007. NAPS '07. 39th North American, pp. 413-420.

Tripathy P., Srivastava S.C., and Singh S.N., 2010, “A Divide-by-Difference-Filter Based Algorithm for Estimation of Generator Rotor Angle Utilizing Synchrophasor Measurements,” IEEE Trans. On Instrumentation and Mesurement, Vol. 59, No. 6, pp. 1562-1570.

US-Canada Power System Outage Task Force, Final Report on 2003 the Blackout in the United States and Canada, 2004. [Online]. Available: https://reports.energy.gov/BlackoutFinal-Web.pdf.

Varma R.K., and Auddy S., 2006, "Migation of Sub synchronous Resonance by SVC using PMU-Acquired Remote Generator Speed,” Power India Conference, IEEE 2006 conference, New Delhi, 2006, pp. 1-8.

Varma R.K., Gupta R.P., and Auddy S., 2007, "Damping of Inter-Area Oscillation in Power Systems by Static Var Compensator (SVC) Using PMU-Acquired Remote Bus Voltage Angles,” International Journal of Emerging Electric Power Systems, Volume 8, Issue 4.

Venkata V.S., and Kavasseri R.G., 2004, "Direct computation of generator internal states from terminal measurements,” in Proc. $37^{\text {th }}$ Annu. Hawaii Int. Conf. Syst. Sci., Big Island, HI.

Xu B., and Abur A., 2004 "Observability analysis and measurement placement for system with PMUs," in IEEE Power System Conference \& Exposition.

Xu T.,Wang P., He R., and Xu D., 2004, "Phasor Measurement Placement for Transient Stability Analysis of Power Systems,” 2004 international Conference on Power System Technology - POWERCON 2004 Singapore, 21-24 November 2004.

Yu C.S., Liu C.W., Yu S.L., and Jiang J A., 2002, “A N ew PMU-Based Fault Location Algorithm for Series Compensated Lines,” IEEE Trans. On Power Delivery, Vol. 17, No. 1, pp.33-46.

Yu C.S., 2006, “A Discrete Fourier Transform-Based Adaptive Mimic Phasor Estimator for Distance Relaying Applications," IEEE Trans. On Power Delivery, Vol. 21, No. 4.

Yu C.S., and Liu C.W., 2002, "Self-correction two-machine equivalent model for stability control of FACT system using real-time phasor measurements,” IEE Proc-Gener. Transm. Distrib., Vol. 149. No. 4, pp. 453-463.

Zamora I., Minambres J., Mazon A., Alvarez-Isasi R., Lazaro J., 1996, Fault location on two-terminal transmission lines based on voltages, IEE Proceedings: Generation, Transmission and distribution, 143(1), 1996, 1-6.

Zarghami M., Mariesa L. C., and Jagannathan S., 2010, "Nonlinear Control of FACTS Controllers for Damping Interarea Oscillations in Power Systems,” IEEE Trans. On Power Delivery, Vol. 25, No. 4.

Zelingher S., Fardanesh B., Uzunovic E.,Meliopoulos A.P.S., and Cokkinides G.N., 2006, "Harmonic monitoring system via GPSsynchronized measurements-Update and new developments,” in Proc. Power Eng. Soc. Gen. Meeting, Jun. 18-22, 7 pp. [CDROM].

Zhang Y., Penn M., Xia T.,Chen L.,Ye Y.,Wu Z., Yuan Z., Wang L., Jason B., Jon B., Richard W. C., and Liu Y.,2010, "WideArea Frequency Monitoring Network (FNET) Architecture and Applications,” IEEE Trans. On Smart Grid, Vol. 1, No. 2, pp. 458-468.

Zhang G., Hirsch P., and Lee S., 2007, “Wide area frequency visualization using smart client technology,” in Proc. IEEE Power Eng. Soc. General Meeting, pp. 1-8. 
Zhao L., and Abur A., 2005. Multiarea State Estimation Using Synchronized Phasor Measurements, IEEE Trans on Power Systems, Vol. 20, No. 2, pp. 456-462.

Zhong Z., Xu C., Billian B. J., Zhang L., Tsai S.J.S., Conners R.W., Centeno V.A., Phadke A.G., and Liu Y., 2005 "Power system frequency monitoring network (FNET) implementation, IEEE Trans. Power Syst., Vol. 20, No. 4, pp. 1914-1921.

Zhou M., Virgilio A. C., James S. T., and Phadke A.G.,2006, "An Alternative for Including Phasor Measurements in State Estimators,” IEEE Trans. On Power Systems, Vol. 21, No. 4, pp. 1930-1937, November 2006.

Zhu J., Abur A., Rice M.J., Heydt G.T., and Meliopoulos S., 2006, Enhanced state estimators-Final project report,” PSERC, Tempe, AZ.

Zivanovic R., and Cairns C., 1996. Implementation of PMU technology in state estimation: An overview, in Proc. IEEE AFRICON, vol. 2, pp. 1006-1011.

\section{Biographical notes}

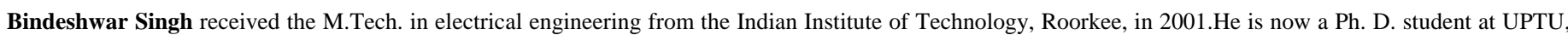

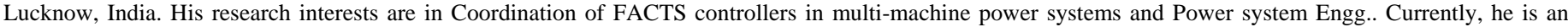

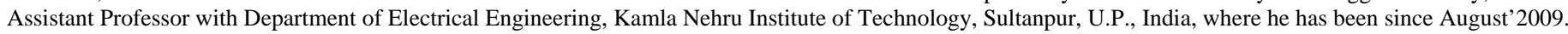
Mobile: 09473795769, 09453503148. Email:bindeshwar_singh2006@rediffmail.com ,bindeshwar.singh2025@gmail.com

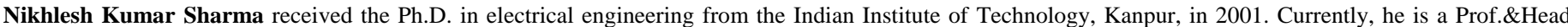

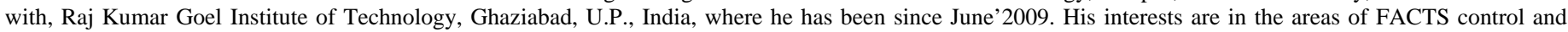
Power systems. Mobile: 09654720667, 09219532281. Email: drnikhlesh@gmail.com

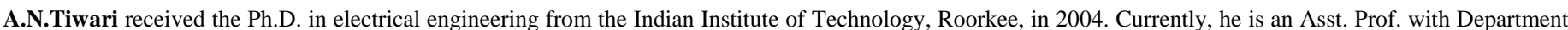

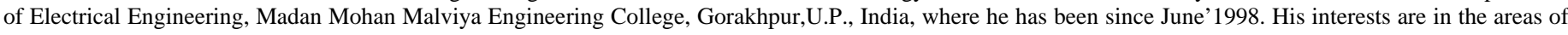
Electrical Drives and Application of Power Electronics. Mobile: 09451215400. Email:amarndee@reffimail.com

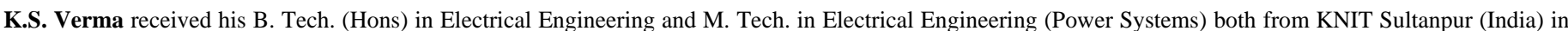

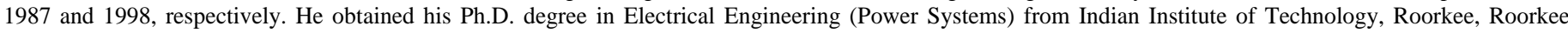

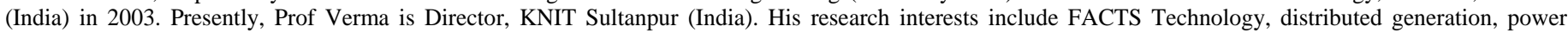
system optimization \& control, power quality and AI application in power system. Email: ksv02@gmail.com

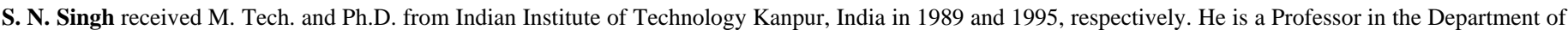

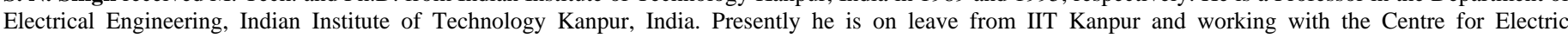

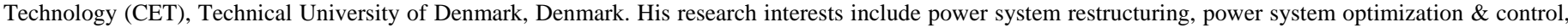

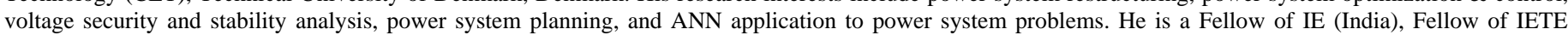
(India) and senior member of IEEE. Email: snsingh@iitk.ac.in

Received January 2011

Accepted March 2011

Final acceptance in revised form April 2011 